\title{
Assessing deployment pathways for greenhouse gas emissions reductions in an industrial plant - A case study for a complex oil refinery
}

\author{
Niels Berghout ${ }^{\mathrm{a}, *}$, Hans Meerman ${ }^{\mathrm{b}}$, Machteld van den Broek ${ }^{\mathrm{a}}$, André Faaij ${ }^{\mathrm{c}}$ \\ ${ }^{\text {a }}$ Copernicus Institute of Sustainable Development, Energy \& Resources, Faculty of Geosciences, Utrecht University, the Netherlands \\ ${ }^{\mathrm{b}}$ Energy Systems Analysis Group, Princeton Environmental Institute, Princeton University, Princeton, USA \\ ${ }^{\mathrm{c}}$ Energy \& Sustainability Research Institute Groningen, University Groningen, the Netherlands
}

\section{H I G H L I G H T S}

- Method to assess pathways for greenhouse gas emissions reductions for industrial plants.

- Method successfully demonstrated for a large, complex oil refinery in Europe.

- We examined energy efficiency, carbon capture and storage, biomass gasification and pyrolysis.

- Pathway with energy efficiency and BIG-CCS is most cost effective and shows deep emissions reductions.

- However, ranking of pathways in terms of costs depends strongly on energy prices.

\section{A R T I C L E I N F O}

\section{Keywords:}

Industry

Refinery

Techno-economic

Energy efficiency

CCS

Biomass

\begin{abstract}
A B S T R A C T
This study developed an integrated method to identify deployment pathways for greenhouse gas emissions reductions in an industrial plant. The approach distinguishes itself by assessing the techno-economic performance of combinations of mitigation options at the level of core processes of an industrial plant. Thus, synergies between mitigation options like economies of scale and negative interactions, such as overlap in emission reduction potential, are incorporated, resulting in more realistic insights into costs and associated risks. The method was successfully applied to a large petroleum refinery $\left(\sim 4.1 \mathrm{MtCO}_{2} / \mathrm{y}\right)$ in northwest Europe. The studied mitigation routes are: energy efficiency measures, carbon capture and storage, fast pyrolysis of woody biomass to produce infrastructure-ready transportation fuels, and gasification of torrefied wood pellets to produce electricity, hydrogen and/or Fischer-Tropsch fuels. Four deployment pathways were examined, all starting with energy efficiency measures and followed by (1) oxyfuel combustion capture, (2) post-combustion capture, (3) biomass gasification, or (4) biomass gasification with carbon capture and storage. Pathway 4 is most cost-effective under medium assumptions, regardless of the emissions reduction target, and allows for deep emissions reductions $\left(6.3 \mathrm{MtCO}_{2}\right.$-eq/y; $154 \%$ reduction compared to the 2012 base case). For a $75 \%$ emissions reduction target, the average avoidance cost of pathway 4 is around $-25 €_{2012} / \mathrm{tCO}_{2}$-eq. In comparison, the second most cost-effective pathway (1) was evaluated at average avoidance cost of $-5 €_{2012} / \mathrm{tCO}_{2}$-eq. However, the ranking of the pathways in terms of avoidance cost depends heavily on future energy prices.
\end{abstract}

\section{Introduction}

To meet the targets set at the climate summit in Paris, the European Union (EU) plans to reduce greenhouse gas (GHG) emissions in the manufacturing industry and petroleum refineries (hereafter jointly referred to as 'industrial sector') by $83-87 \%$ below the
1990 level in 2050 [1]. To this end, a broad portfolio of GHG mitigation options needs to be considered [2]. To date, many studies have investigated the GHG reduction potential at the aggregate or sector level by means of energy efficiency measures (EEMs), e.g. [3-6] carbon capture and storage (CCS), e.g. [8,9], switching to low-carbon energy and raw material supply sources, e.g. [7], or renewable energy

\footnotetext{
* Corresponding author.

E-mail address: niels.berghout@iea.org (N. Berghout).
} 


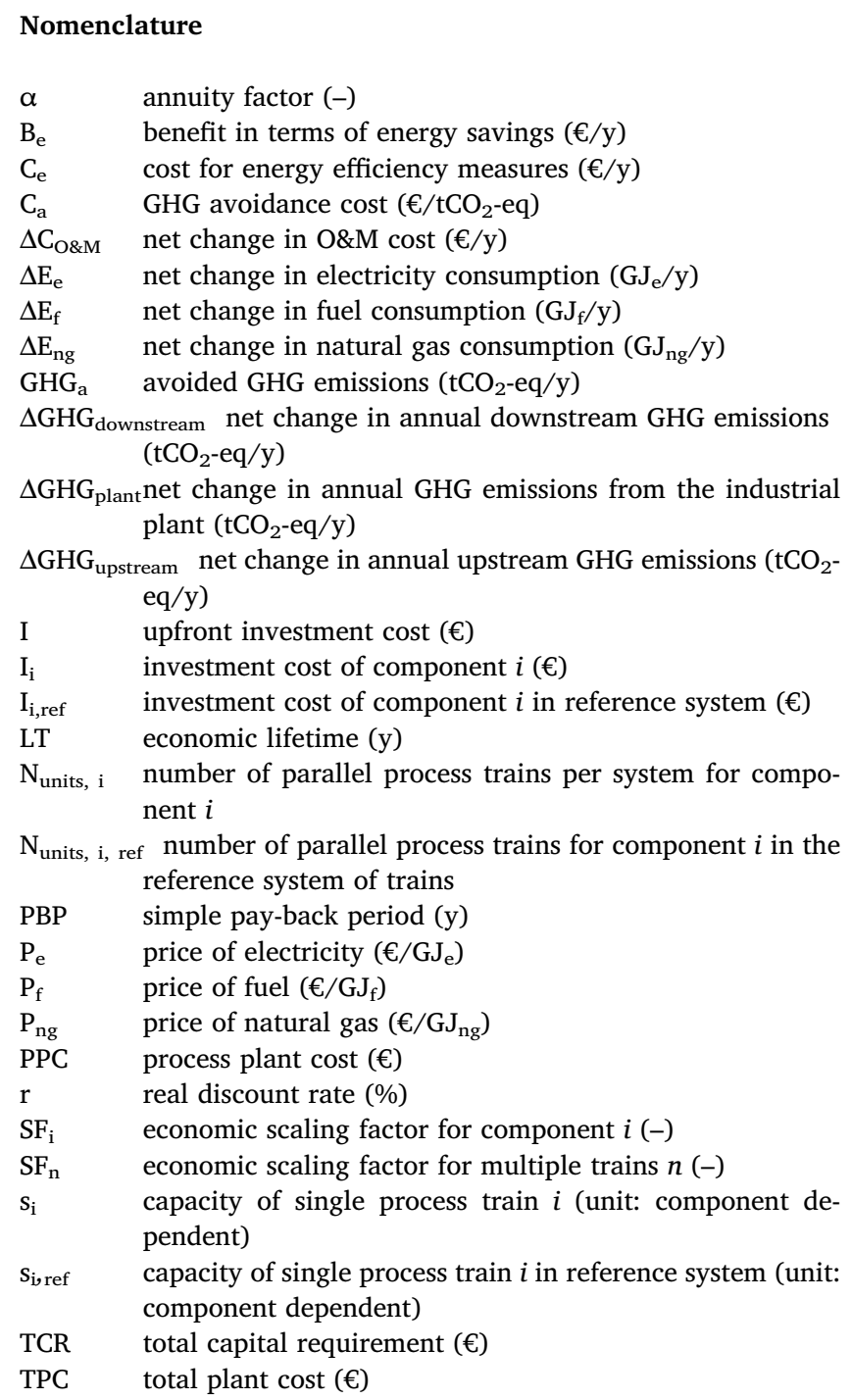

\section{Abbreviations}

\section{DS $\quad 2{ }^{\circ} \mathrm{C}$ scenario of the IEA}

ADIP-X solvent: methyldiethanolamine mixed with piperazine

AGR acid gas removal

ASU air separation unit

ATR autothermal reforming

BF biofuels

BIG biomass gasification

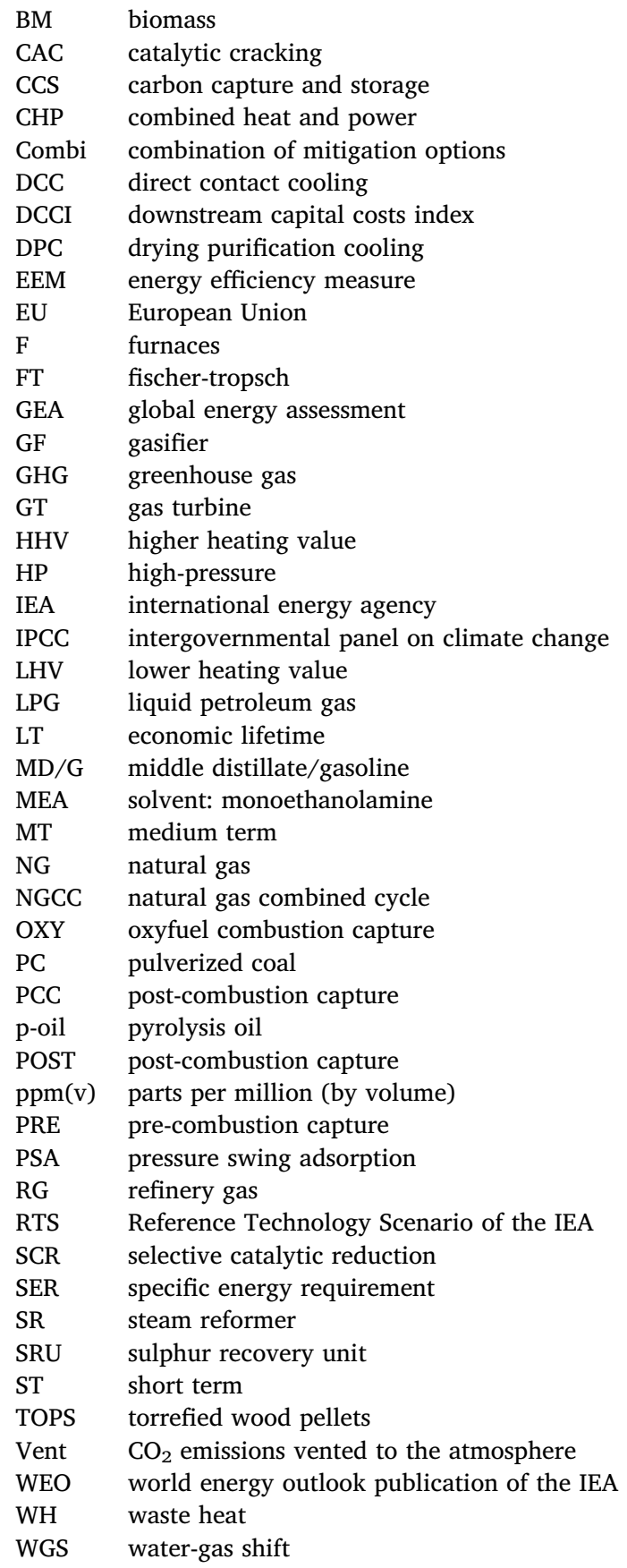

sources, e.g. $[10,11]$. Only few studies have assessed the GHG emissions reduction potential for a combination of mitigation options. Fais et al. [12] assessed the emission reduction potential for different portfolios of options for the UK industry, but did not give any insights into suitable strategies and associated investment costs. Boulamanti and Moya [13] analyzed the potential of various low-carbon energy technologies, including EEMs, CCS and bioenergy, in terms of energy and GHG emissions reductions in the chemical and petrochemical industry of the EU up to 2050. They found that with the adoption of best available and innovative technologies as much as $72.5 \mathrm{MtCO}_{2}$-eq and 225 PJ can be saved annually by 2050, compared to a baseline scenario. Johansson et al. [14] assessed the $\mathrm{CO}_{2}$ reduction potential 
for the European petroleum refining industry up to the year 2050 for EEMs, CCS and fuel switching. Although they acknowledged that different mitigation options affect each other's individual $\mathrm{CO}_{2}$ reduction potential when implemented in tandem, Johansson et al. [14] did not assess the $\mathrm{CO}_{2}$ reduction potential of the mitigation options together, nor did they determine deployment pathways.

Next to high level assessments, numerous studies have investigated the techno-economic performance and $\mathrm{CO}_{2}$ reduction potential at the industrial plant level by means of EEMs, e.g. [15] and CCS [16]. Others studies have assessed the feasibility of biomass gasification and fast pyrolysis to produce energy carriers and chemicals, which could be used as mitigation options in industrial plants $[17,18]$. However, to the authors' knowledge, the implementation of a combined portfolio of mitigation options at the industrial plant level has not yet been evaluated. More insight is required into how to deploy a portfolio of available mitigation options over time (i.e. with low $\mathrm{CO}_{2}$-eq avoidance cost, high GHG emissions reduction, and/or low upfront investment cost). Promising deployment pathways for an industrial plant will depend heavily on, among others, the industrial sector, key processing technologies, (future) plant configuration, fuel and feedstock mix, and energy prices. Several studies have demonstrated that marginal abatement cost curves can be a useful tool to evaluate and identify costeffective GHG mitigation strategies (e.g. [19-21]). However, marginal abatement cost curves suffer from a number of limitations, such as the non-consideration of interactions between mitigation options, a possibly inconsistent baseline, and double counting [22]. This tool should therefore be used in a broader methodological framework when identifying and assessing effective strategies for industrial plants. The method should consider the main process components and allow for assessing different process configurations via different deployment pathways for industrial plants across all sectors.

The objective of this paper is to develop this method based on a bottom-up analysis and to illustrate the method by identifying deployment pathways in the refinery sector up to the year 2030. The time period was limited to 2030 given the large degree of uncertainty in sector developments and costs and performance of technologies in the long term.

\subsection{Oil refining industry}

Within the $\mathrm{EU}$, the oil refining industry accounts for $8 \%$ $\left(155 \mathrm{MtCO}_{2} / \mathrm{y}\right)$ of industrial sector emissions and has a combined processing capacity of around $770 \mathrm{Mt} / \mathrm{y}$ of crude oil [14]. Today, there are over one hundred refineries in the EU27 countries, which range in size from small, simple refineries with low conversion capacity (only naphtha reforming), and therefore few output products (so-called topping or hydroskimming refineries) to large, complex refineries with deep conversion capacity and high flexibility, meaning many different output products [14]. Johansson et al. [14] identified 18 complex refineries in the EU, which have both hydrocracking and catalytic cracking processing units and sometimes also gasification and/or coking capacity to convert heavy fractions into lighter product, power and/or steam. In this study, a large, complex petroleum refinery in North-West Europe was selected as a case study to demonstrate the method. Large, complex refineries are particularly interesting for this study considering their high annual $\mathrm{CO}_{2}$ emissions, variety in point sources, and opportunities for a mixture of mitigation options.
In this paper, the term $\mathrm{CO}_{2}$ emissions is used to refer to the refinery (sector), $\mathrm{CCS}$ and $\mathrm{CO}_{2}$ prices, whereas $\mathrm{GHG}$ emissions refer to emissions reduction potentials $\left(\mathrm{tCO}_{2}-\mathrm{eq} / \mathrm{y}\right)$ and avoidance costs $\left(€ / \mathrm{tCO}_{2}-\mathrm{eq}\right)$.

\section{Method}

\subsection{General approach}

The general approach is divided in two parts: the assessment of the individual mitigation options and the identification of promising deployment pathways.

For the assessment of the individual mitigation options, the next steps were followed:

1. Inventory of key parameters of industrial plant of core process in the industrial plant (e.g. $\mathrm{CO}_{2}$ emissions, capacity, energy flows);

2. Projection of baseline GHG emissions by analyzing future trends (e.g. product demand, product quality requirements);

3. Identification and data collection of GHG emission mitigation options;

4. Identification of interactions between mitigation options (i.e. a decrease in GHG reduction potential, cost synergies, economies of scale, lock-in effect);

5. Assessment of GHG reduction potential and GHG avoidance costs of individual and combi mitigation options;

6. Sensitivity analysis of key parameters.

The mitigation options were divided in short-term measures (i.e. the next 5 years) and medium-term measures (i.e. between 5 and 15 years). Moreover, the mitigation options were assigned to one of the following categories, each with an increasing impact on the current plant layout:

- Add-on measures, whereby the mitigation options do not affect the core processes and throughput of the industrial plant;

- Retrofit measures, which involve modifications to either the core process units, the energy supply units (e.g. furnaces), or both;

- Replacement measures, which imply the replacement of existing process units with advanced units with a lower carbon footprint;

- New concepts that replace the core processes of the industrial plant altogether and have a lower carbon footprint than the reference processes.

After determining the techno-economic performance of the individual mitigation options, several promising deployment pathways were identified that embody different combinations of mitigation options. This allows for the exploration of a palet of pathways that differ with respect to several criteria: average $\mathrm{CO}_{2}$ avoidance cost, GHG emission reduction potential, technological maturity of the mitigation options and their impact on the core processes of the industrial plant. The last two criteria are relevant in terms of risk: technologies that are not yet fully developed may not become available (on time) or may not have the expected performance, while technologies that are closely integrated with the core processes could significantly affect the reliability of these processes. Mitigation options with very poor technoeconomic performance or extremely high uncertainties in the input data are excluded from the pathways. 
The interactions between the mitigation options (i.e. economies of scale, cost synergies, decrease in each other's GHG reduction potential, lock-in effect) are quantified where possible. Economies of scale and cost synergies are accounted for in the cost calculations by using economic scaling factors and specific cost data for the combined application of mitigation options (e.g. biomass and CCS). The cost advantage compared to small scale and single application of mitigation options is made explicit. For the deployment pathways, the overlap in the GHG reduction potential as well as the effect on the avoidance costs of the mitigation options, was determined in two steps: (i) the GHG emission reduction and avoidance cost of the mitigation option that is implemented first is computed; (ii) the GHG emission reductions of the second mitigation option is computed by first subtracting the emission reductions of the first mitigation option from the base case emissions, and subsequently by computing the GHG emission reduction and avoidance cost of the second mitigation option. Lastly, possible lock-in effects of mitigation options are described in a qualitative manner.

\subsection{System boundaries and performance indicators}

The analysis incorporates the costs and GHG emissions related to the net mass and energy flows, i.e. the difference in energy and mass flows between the base case and mitigation options. The feedstock input and main industrial plant product output remain constant. ${ }^{1}$

The annually avoided GHG emissions $\mathrm{GHG}_{a}\left(\mathrm{tCO}_{2}-\mathrm{eq} / \mathrm{y}\right)$ is the main technical indicator in this study. $G H G_{a}$ is expressed using Eq. (1):

$G H G_{a}=\Delta G H G_{\text {upstream }}+\Delta G H G_{\text {plant }}+\Delta G H G_{\text {downstream }}$

where $\Delta G H G_{\text {plant }} \Delta G H G_{\text {up }}$, and $\Delta G H G_{\text {down }}$ are the net change in annual GHG emissions ( $\left.\mathrm{tCO}_{2}-\mathrm{eq} / \mathrm{y}\right)$ of the industrial plant, and upstream and downstream processes, respectively. Life cycle GHG emissions related to a change in the production or consumption of energy carriers were included in the analysis.

The GHG avoidance cost $C_{a}\left(€ / \mathrm{tCO}_{2}\right.$-eq) is the main economic indicator in this study. $C_{a}$ is expressed using Eq. (2):

$C_{a}=\frac{\Delta E_{n g} * P_{n g}+\Delta E_{e} * P_{e}+\Delta E_{f} * P_{f}+\alpha * I+\Delta C_{O \& M}}{\Delta G H G_{a}}$

where $\Delta E_{n g}, \Delta E_{e}$ and $\Delta E_{f}$ are the net change in annual natural gas (GJ $\mathrm{Jg}_{\mathrm{ng}}$ / $\mathrm{y})$, electricity $\left(\mathrm{GJ}_{\mathrm{e}} / \mathrm{y}\right)$, and fuel consumption $\left(\mathrm{GJ}_{\mathrm{f}} / \mathrm{y}\right), P_{n g}, P_{e}$ and $P_{f}$ are the prices of natural gas $\left(€ / G J_{n g}\right)$, electricity $\left(€ / G J_{e}\right)$ and fuel $\left(€ / G J_{f}\right)$, respectively. $I$ is the upfront investment cost $(€), \alpha$ is the annuity factor, and $\Delta C_{O \& M}$ is the net change in O\&M cost $(€ / y)$.

The upfront investment cost $I(€)$ are the total capital requirement (TCR), which comprises cost for equipment, installation, engineering fees, contingencies, owner cost and interest during construction. The TCR is derived by multiplying the process plant cost (PPC), i.e. equipment and installation costs, with typical percentages for the other cost components (see Table 1).

The annualized capital cost is calculated by multiplying the upfront investment cost with an annuity factor (see Eq. (2)). The annuity factor

\footnotetext{
${ }^{1}$ In case of EEM, mainly natural gas and electricity are saved, which are unrelated to the feedstock (i.e. crude oil) input. However, deep energy savings may lead to savings of process fuel gases, which are a by-product of the core refinery processes and thus related to the crude oil feedstock. In principle, these saved process gases could be used as feedstock to produce valuable output products, thereby reducing the required feedstock input. However, this reduction in required feedstock level will be very small. Furthermore, for the sake of consistency, it was assumed that the feedstock input level remains constant and the saved fuel gases are sold to third parties.
}

is a function of the real discount rate $\mathrm{r}(\%)$ and economic lifetime LT (years) of the technology (see Eq. (3)).

$\alpha=\frac{r}{1-(1+r)^{-L T}}$

Only limited recent data on investment costs of EEMs was found in literature; instead, numbers on simple pay-back periods for EEMs are presented more often. Hence, the equation for the simple pay-back period was used to calculate the total capital investment costs:

$P B P=\frac{I}{B_{e}-C_{e}}$

where $I$ is the total capital investment cost $(€), B$ is the annual benefit in terms of energy savings $(€ / y)$, and $C$ is the annual cost $(€ / y)$. The annual costs (C) in the equation were assumed to be zero in this study (see Section 3.3.1). Literature data on simple pay-back periods and energy savings were used to derive the investment costs. Subsequently, the investment costs and energy savings were used to compute the GHG avoidance cost using Eq. (2).

\subsection{Standardization of key parameters}

To enable a fair comparison of the technologies, several underlying parameters were standardized. The following procedure as proposed by Kuramochi et al. [8] was adopted:

1. Indexation. All cost figures were converted to $€_{2012}$. Costs that are reported in other currencies were first converted to Euro using the year-average exchange rate data of OANDA [23] for the year the cost data are reported, and were then escalated to the year 2012 using the Downstream Capital Costs Index (DCCI) [24].

2. Normalization of capital cost figures. As not all studies include the same cost components, fixed percentages were used to correct for the differences. The Total Capital Requirement consists of various components:

- Process Plant Cost (PPC) comprising equipment and installation cost;

- Total Plant Cost comprising PPC, engineering fees and contingencies;

- Owner costs (i.e. costs for pre-production, royalties, inventory capital, land and site preparation) and interest during construction.

3. Scaling of capital cost figures. The capital cost of a system component depends mainly on two factors: the size of the component and the number of parallel components. A generic scaling relation was applied to the capital costs to account for this effect (Eq. (5)). The investment cost of a component $i\left(I_{i}: €\right)$ is expressed as proposed by Larson et al. [25]:

$I_{i}=I_{i, \text { ref }} *\left(\frac{N_{\text {units }, i}}{N_{\text {units }, i, \text { ref }}}\right)^{S F_{n}} *\left(\frac{S_{i}}{S_{i, \text { ref }}}\right)^{S F_{i}}$

where $I_{i, r e f}$ is the reference capital investment $(€), N_{\text {units, } i}$ is the number of parallel process trains per system, $N_{\text {units,I,ref }}$ is the number of parallel process trains in the reference system, $S_{i}$ is the capacity of a single process train (unit: component dependent), $S_{\text {ref }}$ is the reference capacity of a single process train (unit: component dependent), $S F_{n}$ is the scaling factor for multiple trains, and $S F_{i}$ is the economic scaling factor for component $i$.

Table 1 provides an overview of the general parameters used in this study. The value ranges of these parameters used for the sensitivity analysis are presented in Table 7 in Section 3.5. 
Table 1

General techno-economic input parameters used in this study.

\begin{tabular}{|c|c|c|c|}
\hline & Unit & Value & References \\
\hline Real discount rate & $\%$ & 10 & Own value \\
\hline Total Plant Cost ${ }^{\mathrm{a}}$ & \%-PPC & 130 & {$[68]$} \\
\hline Calorific value natural gas & $\mathrm{MJ}_{\mathrm{LHV}} / \mathrm{m}^{3}$ & 31.7 & [69] \\
\hline \multicolumn{4}{|l|}{ Industrial energy price } \\
\hline Transport fuels ${ }^{b}$ & $€ / \mathrm{GJ}_{\mathrm{LHV}}$ & 16 & {$[2]$} \\
\hline Natural gas ${ }^{\mathrm{c}}$ & $€ / \mathrm{GJ}_{\mathrm{LHV}}$ & 10 & {$[2]$} \\
\hline Electricity $^{\mathrm{d}}$ & $€ / \mathrm{GJ}_{\mathrm{e}}$ & 22 & [70] \\
\hline Steam (LHV) ${ }^{\mathrm{e}}$ & $€ / \mathrm{GJ}_{\mathrm{th}}$ & 12 & Own value \\
\hline Torrefied wood pellets (TOPS) ${ }^{\mathrm{f}}$ & $€ / \mathrm{GJ}_{\mathrm{LHV}}$ & 8.0 & {$[42,71]$} \\
\hline Woody biomass for pyrolysis & $€ / \mathrm{GJ}_{\mathrm{LHV}}$ & 3.5 & [44] \\
\hline \multicolumn{4}{|l|}{$\mathrm{CO}_{2}$ emission factor } \\
\hline Natural gas & $\mathrm{kgCO}_{2} / \mathrm{GJ}_{\mathrm{LHV}}$ & 56.7 & {$[72]$} \\
\hline \multicolumn{4}{|l|}{ Life cycle GHG emissions } \\
\hline Electricity grid production ${ }^{g}$ & $\mathrm{kgCO}_{2}-\mathrm{eq} / \mathrm{GJ}_{\mathrm{e}}$ & 63 & [73] \\
\hline Torrefied wood pellets (TOPS) ${ }^{\mathrm{h}}$ & $\mathrm{kgCO}_{2}-\mathrm{eq} / \mathrm{GJ}_{\mathrm{LHV}}$ & 7.9 & [74-76] \\
\hline Fossil gasoline & $\mathrm{kg} \mathrm{CO}-\mathrm{eq} / \mathrm{GJ}_{\mathrm{LHV}}$ & 79.4 & {$[52]$} \\
\hline Fossil diesel & $\mathrm{kg} \mathrm{CO} 2-\mathrm{eq} / \mathrm{GJ}_{\mathrm{LHV}}$ & 80.3 & {$[52]$} \\
\hline Natural gas & $\mathrm{kg} \mathrm{CO}-\mathrm{eq} / \mathrm{GJ}_{\mathrm{LHV}}$ & 66.3 & {$[52]$} \\
\hline Industrial furnace efficiency ${ }^{i}$ & $\%$ & 80 & {$[78]$} \\
\hline Max. NGCC-CHP efficiency (LHV) ${ }^{\mathrm{j}}$ & $\%$ & 90 & {$[79,80]$} \\
\hline Power equivalent factor LP steam & & 0.28 & {$[80]$} \\
\hline
\end{tabular}

a Process plant cost (PPC) comprises equipment and installation costs. Total plant cost (TPC) comprises PPC, engineering fees and contingencies. Total capital requirement (TCR) comprises TPC, owner costs and interests during construction. The values are within observed ranges for power plant construction [8].

b The transport fuel price was based on projected developments in the crude oil price as reported in the Energy Technology Perspectives publication of the IEA [2]. A price range of 60-100 €/bbl was observed for the period 2020-2040 in the Reference Technology Scenario (RTS) and $2{ }^{\circ} \mathrm{C}$ Scenario (2DS), which reflect varying assumptions on energy and climate policy, technology deployment and economic and demographic changes. The method of Knoope et al. [18] was adopted to derive the costs of the transport fuel price for the year 2025 . Using a conversion factor of $6.12 \mathrm{GJ} \mathrm{HHV}_{\mathrm{H}} / \mathrm{bbl}$ [81] and a HHV/LHV ratio of 1.06 [82], the ETP prices translate to a crude oil price range of $11-18 € / \mathrm{GJ}_{\mathrm{LHV}}$. The costs for crude oil refining to obtain gasoline and diesel were indicated by Larson et al. [25] to be $27 € / \mathrm{m}^{3}$ diesel. With a volume of $0.159 \mathrm{~m}^{3} / \mathrm{bbl}_{\text {, this equates to a margin of } 0.8 € / \mathrm{GJ}} \mathrm{LHV}$. Using the crude oil price range of $81-96 € / \mathrm{bbl}$, the costs of fossil diesel and gasoline production are projected to be $12-19 € / \mathrm{GJ}$ LHV A price of $16 € /$ $\mathrm{GJ}_{\mathrm{LHV}}$ was used as medium value in this study. Infrastructure-ready green transport fuels were assumed to fetch similar prices on the transport fuel market as their fossil counterparts.

c This was based on projected natural gas price developments as reported in the Energy Technology Perspectives publication [2]. A price range of $7-11 € /$ GJ was observed for the period 2020-2040 in Europe in the Reference Technology Scenario (RTS) and $2^{\circ} \mathrm{C}$ Scenario (2DS). A conservative price of $10 € / \mathrm{GJ}_{\mathrm{LHV}}$ was used as medium value for natural gas. As the country in which the case study is based has to significantly reduce natural gas production volumes over the coming decades, this relatively high natural gas price is deemed to be realistic.

d It was assumed that in a world where GHG mitigation measures like CCS and biomass technologies are deployed for industrial processes, the North-West European power sector is already largely decarbonised. Therefore, projected electricity prices were taken from Brouwer et al. [70], who modelled several low-carbon power systems for Western Europe with varying shares of variable renewable electricity and fossil power plant CCS using hourly power system simulation software. They found electricity prices of around $80 € / \mathrm{MWh}(22 € / \mathrm{GJ})$ for different power system configurations. The main reason for the high electricity price, compared to today's prices, is the high investment needs required for the large-scale deployment of lowcarbon technologies across the power sector, which need to be recuperated by investors through an electricity price increase.

e It was assumed that the onsite steam production costs in an industrial boiler equal the steam price. Based on a natural gas price of $10 € / \mathrm{GJ} \mathrm{LHV}_{\mathrm{LH}}$ boiler capital costs of $85 € / \mathrm{kW}$ [83] and boiler O\&M costs of $2 \%$ of the total investment costs, the production costs of high-pressure steam were calculated to be $11.8 € / \mathrm{GJ}_{\mathrm{LHV}}$. This figure is in line with steam prices $\left(11.1 € / \mathrm{GJ}_{\mathrm{LHV}}\right)$ indicated for industry [84].

f The method of Meerman et al. [42] was adopted to derive the medium value for the TOPS price. Albeit TOPS are not produced commercially today, Meerman et al. [42] used biomass pellet prices as a proxy for TOPS prices, assuming that the additional production costs of torrefaction compared to biomass pellets are compensated by the reduction in transportation costs. Assuming an energy density of $17 \mathrm{GJ} \mathrm{LHV}_{\mathrm{L}} \mathrm{t}$ [85], biomass pellet prices fluctuated between 6.9 and $8.8 € / \mathrm{GJ}_{\mathrm{LHV}}$ during the period 2007-2013 [42,71]. A medium value of $8.0 € / \mathrm{GJ}_{\mathrm{LHV}}$ was used for this study.

$g$ This is the $\mathrm{CO}_{2}$ emission factor for the electricity mix in 2020-2030 as modelled in the Grand Coalition scenario by van den Broek et al. [73], which is based on the premise that a large share of the $\mathrm{CO}_{2}$ is reduced through renewable energy technologies and other $\mathrm{CO}_{2}$ mitigation options. This scenario was assumed to be a precondition for large scale deployment of GHG mitigation options at industrial processes.

h Taken from Batidzirai et al. [74-76] who presented data on supply chain GHG emissions of TOPS made from eucalyptus and switchgrass in Mozambique, eucalyptus in Brazil, and agricultural residues in South Africa. The supply chain includes biomass production, chipping, drying, torrefaction, milling, pelletizing, and transport by truck, train and sea ship.

${ }^{i}$ In case efficiencies for industrial furnaces were not indicated, an average efficiency of $80 \%$ was assumed.

$\mathrm{j}$ The gas turbine electrical efficiency is assumed to be two-thirds of the NGCC efficiency in condensing mode.

\section{Case study}

\subsection{Complex oil refinery}

A large, complex oil refinery in North-West Europe was selected as a case study due to its large processing capacity (over 20 Mt crude oil in
2012), high $\mathrm{CO}_{2}$ emissions ( $\sim 4 \mathrm{MtCO}_{2} / \mathrm{y}$ in 2012), variety in size and spatial distribution of point sources, and large potential for various GHG mitigation options. The key characteristics of the refinery are shown in Table 2 . The refinery is capable of processing a high number of crude oil types and shows high flexibility in the conversion routes and portfolio of final output products. The key processes of the refinery 
Table 2

Key characteristics of the case refinery in 2012 . $^{\text {a }}$

\begin{tabular}{|c|c|c|c|}
\hline & Unit & Value & References \\
\hline Crude oil throughput & $\mathrm{Mt} / \mathrm{y}$ & $\sim 20$ & {$[26]$} \\
\hline Annual $\mathrm{CO}_{2}$ emissions & $\mathrm{Mt} / \mathrm{y}$ & 4.1 & [67] \\
\hline Estimated primary energy input $\mathrm{CHP}^{\mathrm{b}}$ & $\mathrm{PJ}_{\mathrm{p}} / \mathrm{y}$ & $\sim 16$ & {$[26,67]$} \\
\hline Estimated electricity production $\mathrm{CHP}^{\mathrm{b}}$ & $\mathrm{PJ}_{\mathrm{e}} / \mathrm{y}$ & $\sim 5$ & {$[26,67]$} \\
\hline Estimated steam production $\mathrm{CHP}^{\mathrm{b}}$ & $\mathrm{PJ}_{\mathrm{th}} / \mathrm{y}$ & $\sim 9$ & {$[26,67]$} \\
\hline Estimated hydrogen production $\mathrm{SR}^{\mathrm{c}}$ & $\mathrm{PJ}_{\mathrm{H} 2} / \mathrm{y}$ & $\sim 7$ & {$[26,67]$} \\
\hline Number of stacks & & 18 & [67] \\
\hline \multicolumn{4}{|l|}{ Volumetric $\mathrm{CO}_{2}$ concentration ${ }^{\mathrm{d}}$} \\
\hline Gasifier & $\%$-vol & 99 & [86] \\
\hline SR WGS-PSA ${ }^{\mathrm{e}}$ & $\%$-vol & $30-60$ & [37] \\
\hline SR furnace stack & $\%$-vol & $5-10$ & [37] \\
\hline Catalytic cracker ${ }^{\mathrm{f}}$ & $\%$-vol & $10-20$ & [87] \\
\hline Furnaces & $\%$-vol & $8-12$ & [86] \\
\hline Gas turbines & $\%$-vol & 4 & [86] \\
\hline
\end{tabular}

a The process heat demand in the refinery is not presented for reasons of confidentiality.

b Based on a total in situ CHP input capacity of $560 \mathrm{MW}$, an operation time of $8000 \mathrm{~h} / \mathrm{y}$, and an assumed average electric and thermal efficiency of 33\% and $56 \%$, respectively. The internal consumption and production of electricity were assumed to be equal, i.e. no electricity import or export takes place.

c Natural gas was assumed to be the main fuel and feedstock for the in situ SR to produce hydrogen. Based on the fuel input capacity, a capacity factor of $56 \%$, a calorific value of $121 \mathrm{MJ}_{\mathrm{LHV}} / \mathrm{tH}_{2}$, a SR efficiency of $75 \%$ [88] and a ratio between the natural gas used for fuel and feedstock of around 1:2.9 [88], the hydrogen production was estimated to be around $7 \mathrm{PJ} / \mathrm{y}$. The capacity factor was derived from the SR furnace capacity and annual fuel gas input.

d The values for the volumetric $\mathrm{CO}_{2}$ concentrations are based on generic data, which do not apply specifically to the case refinery.

e WGS and PSA stand for watergas shift and pressure swing adsorption, respectively.

$\mathrm{f}$ The high-temperature flue gas from the catalytic cracker contains typically around $10-20$ vol $\% \mathrm{CO}_{2}$ when running on a full combustion mode (excess air in the regenerator) [87]. A conservative value of $12 \mathrm{vol} \%$ was used in this study.

are crude oil distillation, conversion of oil fractions in the catalytic reformer, (hydro, catalytic and thermal) crackers and gasifier, and desulphurization of the intermediate and final products. The refinery has been expanded, upgraded and rejuvenated several times during its lifetime [26]. A schematic overview of the refinery and $\mathrm{CO}_{2}$ emissions is presented in Figs. 1 and 2, respectively. The $\mathrm{CO}_{2}$ emissions are vented via 18 stacks and two flares, which have different mass flows and volumetric $\mathrm{CO}_{2}$ concentrations. The majority of the $\mathrm{CO}_{2}$ emissions are attributed to the process furnaces, followed by the gas turbine/CHP units, ${ }^{2}$ and gasifier. The gas turbine, CHP units, steam reformer (SR), and gasifier on the refinery site will hereafter be referred to as in situ technology to distinguish them from newly built CHP units, reformers and gasifiers, which are required for the mitigation options.

\subsection{Future trends}

Market trends were analyzed to make projections for the baseline GHG emissions for the short and medium term. These trends were analyzed by reviewing trend forecasts studies from international organizations and academia [27,28] and industry organizations [29,30]. The review, analysis and data underlying the $\mathrm{CO}_{2}$ emission projections are described in detail in the Appendix. The following trends are relevant for the case refinery:

- There will be a global shift in demand from heavy (i.e. fuel oils and marine fuels) and light distillates (i.e. gasoline and naphtha) to middle distillates (i.e. diesel and jet fuel). Despite the projected lower crude oil demand in the EU, the specific refinery energy consumption and $\mathrm{CO}_{2}$ emissions are expected to rise due to higher demand for middle distillates.

- EU legislation on fuel quality (mainly sulphur) will become more stringent in the future. Stricter quality specifications will result in higher specific energy requirement and concomitant $\mathrm{CO}_{2}$ emissions in EU refineries.

Based on quantitative projections of the CONCAWE association $[29,31]$, the case refinery $\mathrm{CO}_{2}$ emissions were estimated to increase with $0.3 \mathrm{MtCO}_{2} / \mathrm{y}$ in the short term as a result of the increasing middle distillates/gasoline $(\mathrm{MD} / \mathrm{G})$ ratio. Another increase of $0.3 \mathrm{MtCO}_{2} / \mathrm{y}$ was projected for the medium term. The planned stricter quality regulations are expected to increase refinery $\mathrm{CO}_{2}$ emissions with $11 \%$ in the short term $\left(0.5 \mathrm{MtCO}_{2} / \mathrm{y}\right)$ compared to 2012 levels. Additional legal changes may be introduced in the medium term. These changes could result in an increase of $16 \%\left(0.6 \mathrm{MtCO}_{2} / \mathrm{y}\right)$ in the refinery's $\mathrm{CO}_{2}$ emissions compared to 2012 levels.

The economic performance of the mitigation options are compared with a $\mathrm{CO}_{2}$ price range of $20-75 € / \mathrm{tCO}_{2}$, which is based on $\mathrm{CO}_{2}$ price projections for the short and medium term in three scenarios (Current Policies, New Policies and Sustainable Development) of the IEA's World Energy Outlook (WEO) 2017 [32], each founded on varying assumptions on energy and climate policy, technology deployment and economic and demographic changes. The Current Policies scenario represents a development in which there are no changes in the established policies. In the New Policies scenario, it is assumed that a broad set of the policy commitments and plans that have been announced by countries to reduce GHG emissions will come into effect. The Sustainable Development scenario takes into account all ambitious policies and measures needed to achieve the $450 \mathrm{ppmv}$ target, while also reducing air pollutant emissions and achieving universal energy access. More information about the scenarios can be found in WEO 2017 [32].

\subsection{GHG mitigation options and data collection}

The selected mitigation options are: energy efficiency measures, $\mathrm{CO}_{2}$ Capture and Storage and the switch of natural gas to biomass, both as feedstock and as fuel. The following mitigation options were excluded from the analysis due to a lack of detailed data required to perform the analysis:

- Switch to lighter crude oil fractions to reduce the energy use and concomitant $\mathrm{CO}_{2}$ emissions in the processing steps.

- Utilization of waste heat (WH) that cannot be used in the core refinery processes. Previous research has shown that process integration with adjacent industries as well as using low-temperature $\mathrm{WH}$ for post-combustion solvent regeneration, district heating, or biomass drying could result in significant $\mathrm{CO}_{2}$ emissions reductions $[14,33]$.

- The use of geothermal energy for process or fuel heating.

The selected mitigation options are described in the following subsections. A more detailed description of the technologies and the assumptions and data underlying the calculations can be found in the Appendix.

\subsubsection{Energy efficiency measures}

Several opportunities for EEMs were identified for the refinery based on the current plant configuration. Data on energy savings, payback periods and economic lifetime were taken from the Energy Guide on available EEMs for petroleum refineries [34]. The data are mainly based on case studies from U.S. refineries around the year 2010.

\footnotetext{
${ }^{2}$ The refinery has four gas turbines; three of them are CHP units.
} 


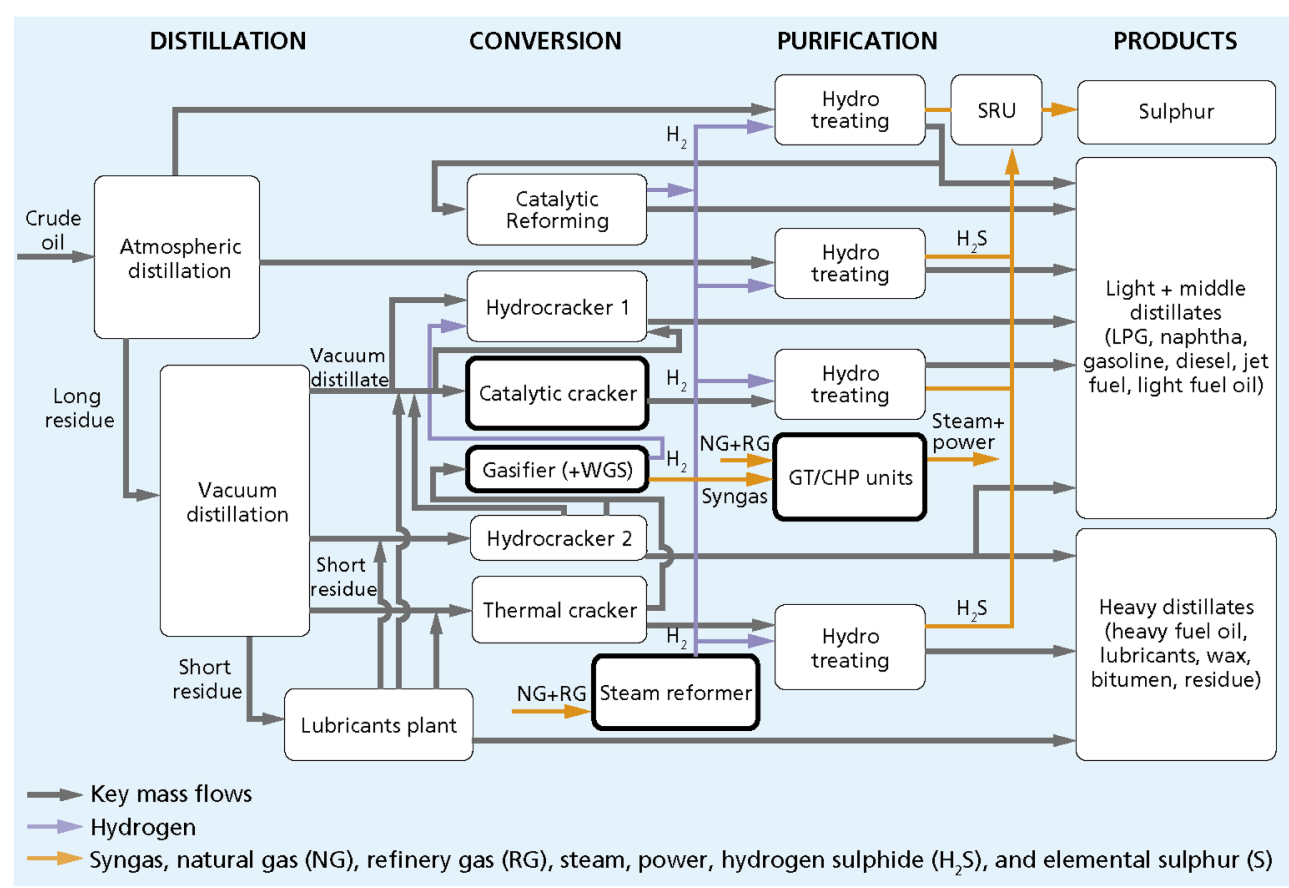

Fig. 1. Simplified process layout of the case refinery. The main $\mathrm{CO}_{2}$ emission sources in the refinery are depicted in bold. The other two $\mathrm{CO}_{2}$ emission sources (furnaces and flares) are not displayed. GT, CHP, LPG, SRU, WGS stand for gas turbine, combined heat power, liquid petroleum gas, sulphur recovery unit, and watergas shift, respectively.

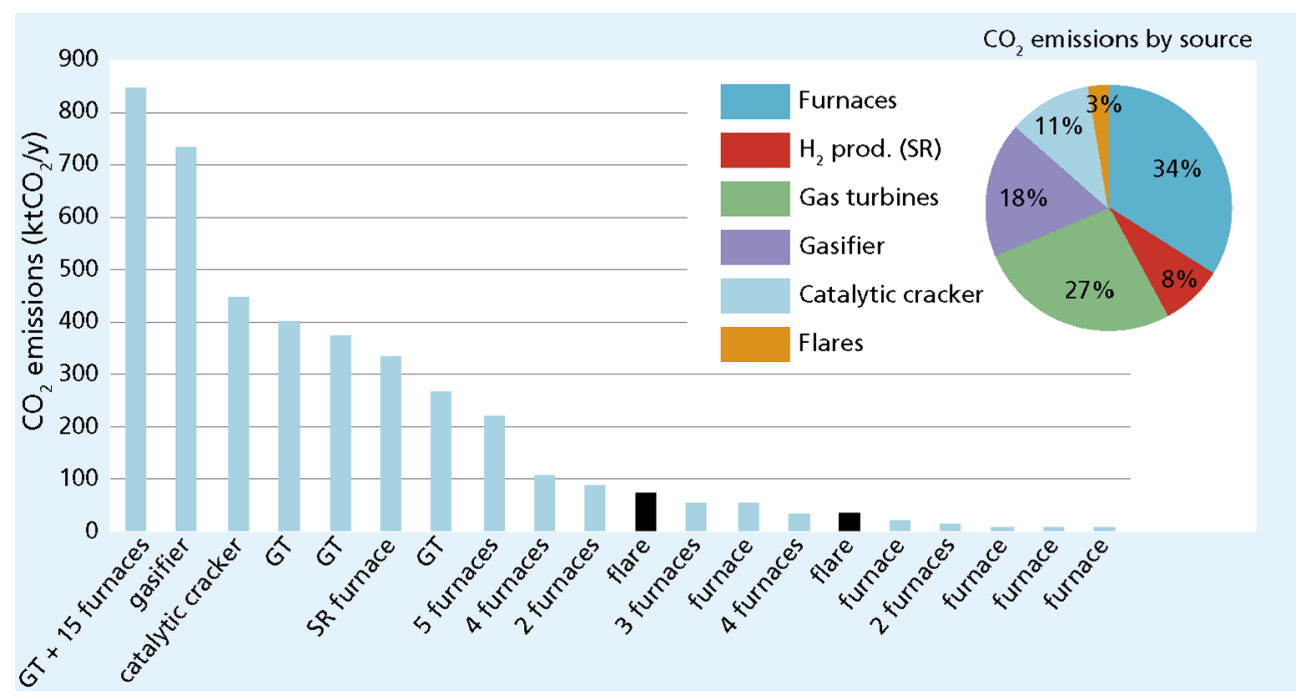

Fig. 2. $\mathrm{CO}_{2}$ point sources (bar chart) and breakdown of $\mathrm{CO}_{2}$ emissions by source (pie chart), both for the year 2012 [67]. The process units related to the stacks are presented on the horizontal axis; each bar represents one stack (blue bar) or flare (black bar). GT stands for gas turbine.

Table 3

Primary energy reduction potential for the refinery for the short and medium term. The data are based on Worrell et al. [34]. The reductions are related to the total primary energy use in the refinery in the year 2012, thus excluding growth in emissions due to future trends.

\begin{tabular}{|c|c|c|c|c|c|}
\hline Short term EEMs & $\mathrm{PJ} / \mathrm{y}$ & $\%$ & Medium term EEMs & $\mathrm{PJ} / \mathrm{y}$ & $\%$ \\
\hline Energy management \& control & 1.7 & 3.0 & Advanced desulphurization & 5.8 & 10.0 \\
\hline Heat integration distillation units & 1.7 & 3.0 & Advanced separation systems & 3.9 & 6.8 \\
\hline Motors \& pumps & 1.4 & 2.4 & Turbine pre-coupling & 1.5 & 2.5 \\
\hline Steam distribution system & 1.2 & 2.0 & & & \\
\hline Heat integration \& waste heat recovery & 1.2 & 2.0 & & & \\
\hline Fouling mitigation & 0.6 & 1.0 & & & \\
\hline Improved furnace performance & 0.6 & 1.0 & & & \\
\hline Hydrogen management \& recovery & 0.4 & 0.7 & & & \\
\hline Flaring & 0.3 & 0.5 & & & \\
\hline Total & 9.1 & 15.6 & Total & 11.2 & 19.3 \\
\hline
\end{tabular}


Changes in the annual costs of the process units due to the implementation of EEMs were neglected in this study. ${ }^{3}$

For the short term, nine EEMs were identified (see Table 3). The largest primary energy reductions can be achieved via heat integration between the distillation units $(\sim 3 \%)$ and improvements in energy management \& control $(\sim 3 \%)$. The joint primary energy reduction of short term EEMs amounts up to $15-16 \%$. For the medium term, three EEMs were identified, with advanced desulphurization systems showing the largest primary energy reductions $(\sim 10 \%)$. In total, an estimated reduction in primary energy use of $19-20 \%$ was computed for the medium term. Whereas the short term EEMs can be implemented by retrofitting process units in the current refinery layout, two of the medium term EEMs (advanced separation and desulphurization systems) have a higher impact on the refinery layout as it requires the replacement of current core process units (distillation and hydrotreating units). Ideally, these units would be installed by the time the current process units have to be replaced.

\subsection{2. $\mathrm{CO}_{2}$ capture and storage}

Three first generation $\mathrm{CO}_{2}$ capture technologies are assessed: post-, pre- and oxyfuel combustion capture. While post-combustion capture is an add-on technology, pre- and oxyfuel combustion are considered to be retrofit technologies that require additional equipment and adjustments to the existing refinery infrastructure [35]. The key data of the $\mathrm{CO}_{2}$ capture technologies can be found in Table 4 .

Post-combustion capture is applied to the main $\mathrm{CO}_{2}$ sources on the refinery site: furnaces, catalytic cracker, in situ CHP unit, and the in situ hydrogen plant. Oxyfuel and pre-combustion technology are applied to all these sources, except to the in situ hydrogen plant (no oxyfuel combustion) and catalytic cracker (no pre-combustion), respectively, due to technological constraints. Although some gas turbines display operational difficulties when fired with nearly pure oxygen or hydrogen [36], it is assumed these issues will be solved in the medium term. required. The in situ hydrogen plants are also retrofitted with chemical scrubbers (ADIP-X) to capture $\mathrm{CO}_{2} \cdot \mathrm{CO}_{2}$ capture from the in situ refinery gasifier, which processes catalytic cracker residue, does not require a specific technology as the separation of the $\mathrm{CO}_{2}$ is already an inherent part of the gasification process. In all capture routes, the $\mathrm{CO}_{2}$ is cooled, dried, purified and compressed to 110 bar before it is transported to a storage site. An economic lifetime of 20 years was used for all three capture technologies $[37,38]$.

\subsubsection{Biomass utilization}

Balat et al. [39] and Faaij [40] distinguished three main thermochemical conversion routes for biomass: gasification, pyrolysis and combustion. As the refinery units are mainly fueled with refinery gases, (solid) biomass combustion does not seem to be a realistic option. Therefore, only the first and second options were considered in this study. Both options are new concepts that differ from the core refinery process.

3.3.3.1. Biomass gasification. The first biomass route is the production of syngas through biomass gasification (BIG) from torrefied wood pellets (TOPS) with its favorable properties of a high heating value and low moisture content. Next, syngas is converted to steam and electricity in the BIG-CHP sub-route, to hydrogen in the BIG- $\mathrm{H}_{2}$ subroute, and to Fischer-Tropsch (FT) fuels in the BIG-FT sub-route. In BIGCHP the hydrogen completely replaces the natural gas for the in situ gas turbine and CHP units in the refinery and in BIG- $\mathrm{H}_{2}$, it replaces the hydrogen from the in situ SR. In BIG-FT, the FT-fuels are produced in addition to the fossil gasoline and diesel made in the refinery, and is assumed to replace fossil diesel and gasoline in other less efficient refineries. In this sub-route the upgrading process of the FT-process occurs in a new hydrocracker and distillation columns as it is unknown whether the existing units on the refinery site have spare throughput capacity. Moreover, integration of the FT-process with the existing units

Table 4

Techno-economic parameters for $\mathrm{CO}_{2}$ capture and storage.

\begin{tabular}{|c|c|c|c|c|c|}
\hline & Unit & Post-combustion & Oxyfuel combustion & Pre-combustion & References \\
\hline \multicolumn{6}{|l|}{ Technical } \\
\hline $\mathrm{CO}_{2}$ capture ratio & $\%$ & 87 & 87 & $95^{\mathrm{a}}$ & {$[45]$} \\
\hline \multirow[t]{2}{*}{ Spec. electricity use } & $\mathrm{GJ}_{\mathrm{e}} / \mathrm{tCO}_{2}$ & $1.0-1.3^{\mathrm{b}}$ & 0.5 & 0.4 & {$[37,89-93]$} \\
\hline & $\mathrm{GJ}_{\mathrm{e}} / \mathrm{tO}_{2}$ & - & 0.7 & - & [94] \\
\hline Spec. heat use ${ }^{b}$ & $\mathrm{GJ}_{\mathrm{th}} / \mathrm{tCO}_{2}$ & $3.5-4.0^{\mathrm{b}}$ & - & $1.97^{\mathrm{a}}$ & {$[37,95]$} \\
\hline Natural gas use & $\mathrm{GJ}_{\mathrm{p}} / \mathrm{tH}_{2}$ & - & - & 165 & {$[88]$} \\
\hline \multicolumn{6}{|l|}{ Economics } \\
\hline \multirow[t]{2}{*}{ Specific capital cost ${ }^{c}$} & $\mathrm{M} € / \mathrm{MtCO}_{2} / \mathrm{y}$ & $\begin{array}{l}101 \text { (4 vol\%); } \\
75(12-14 \text { vol\%) }\end{array}$ & 42 & 130 & [45] \\
\hline & $\mathrm{M} € / \mathrm{ktO}_{2} / \mathrm{y}$ & - & 53 & - & [45] \\
\hline \multirow[t]{2}{*}{ Specific O\&M cost } & $€ / \mathrm{tCO}_{2}$ & 4.8 & 9.0 & 7.1 & [45] \\
\hline & $€ / \mathrm{tH}_{2}$ & - & - & 4.5 & {$[45]$} \\
\hline Maintenance cost & $\%$ of TPC & 3.8 & - & - & [96] \\
\hline $\mathrm{CO}_{2}$ transport and storage costs & $€ / \mathrm{tCO}_{2}$ & 16 & 16 & 16 & {$[61,62]$} \\
\hline
\end{tabular}

a This applies to $\mathrm{CO}_{2}$ capture from the high-pressure process gas after the PSA unit.

b Regeneration heat and electricity needed for flue gas with volumetric $\mathrm{CO}_{2}$ concentrations in the range of $4-16 \%$; the specific regeneration energy $\left(\mathrm{GJ}\right.$ th $/ \mathrm{tCO}_{2}$; $\mathrm{GJ}_{\mathrm{e}} / \mathrm{tCO}_{2}$ ) decreases with higher volumetric $\mathrm{CO}_{2}$ concentrations.

c This excludes capital cost for required modifications to the flue gas stacks of $0.1 \mathrm{M} € /$ stack [78].

Deploying pre-combustion capture across the refinery would require additional SR's as the in situ SR plants will most likely not have sufficient production capacity to deliver the large amounts of hydrogen

\footnotetext{
${ }^{3}$ The sensitivity analysis shows the effect of a change in the annual energy savings and natural gas price on the $\mathrm{CO}_{2}$-eq avoidance costs. Considering the large uncertainty in the gas price and annual energy savings, the effect of a change in annual costs due to the implementation of an EEM (typically $\pm 5 \%$ of the investment costs [34]) on the $\mathrm{CO}_{2}$-eq avoidance costs will be minor.
}

would require detailed data on the refinery processes, which is not publicly available. The BIG-FT option was limited to $1000 \mathrm{MW}_{\mathrm{HHV}}$ of TOPS feed input because larger plant scales would hardly lower production costs [41]. ${ }^{4}$

Finally, a fourth sub-route, BIG-combi, combines the other 3 BIG

\footnotetext{
${ }^{4}$ The $1000 \mathrm{MW}_{\mathrm{HHV}}$ input TOPS results in an FT output capacity of $458 \mathrm{MW}_{\mathrm{FT}}$, which corresponds to around $13 \mathrm{PJ} / \mathrm{y}\left(\sim 2.9 * 10^{5}\right.$ toe/y; $1 \%$ of the refinery's crude oil input).
} 
Table 5

Input data for biomass gasification sub-routes. Based on NEA [26,67] and Meerman et al. [42,43].

\begin{tabular}{|c|c|c|c|c|c|c|c|c|c|c|}
\hline & \multirow[t]{2}{*}{ Unit } & \multirow[t]{2}{*}{ REF } & \multicolumn{2}{|c|}{ BIG-CHP } & \multicolumn{2}{|c|}{ BIG- $\mathrm{H}_{2}$} & \multicolumn{2}{|l|}{ BIG-FT } & \multicolumn{2}{|c|}{ BIG-combi } \\
\hline & & & Vent & CCS & Vent & CCS & Vent & CCS & Vent & CCS \\
\hline \multicolumn{11}{|c|}{ Input refinery } \\
\hline Natural gas ${ }^{\mathrm{a}}$ & $\mathrm{MW}_{\mathrm{LHV}}$ & 1167 & 607 & 607 & 560 & 560 & 1167 & 1167 & 0 & 0 \\
\hline TOPS & $\mathrm{MW}_{\mathrm{LHV}}\left(\mathrm{MW}_{\mathrm{HHV}}\right)$ & - & 473 & 511 & 401 & 401 & $\begin{array}{l}937 \\
(1000)\end{array}$ & $\begin{array}{l}937 \\
(1000)\end{array}$ & 1499 & 1499 \\
\hline \multicolumn{11}{|c|}{ Output refinery } \\
\hline Steam & $\mathrm{MW}_{\text {th }}$ & 314 & 314 & 314 & $406^{\mathrm{b}}$ & $406^{\mathrm{b}}$ & 314 & 314 & 314 & 314 \\
\hline Elec. CHP & $\mathrm{MW}_{\mathrm{e}}$ & 182 & 72 & 51 & 156 & 149 & $308^{c}$ & $286^{\mathrm{c}}$ & 86 & 86 \\
\hline Hydrogen & $\mathrm{MW}_{\mathrm{H} 2}$ & 255 & 255 & 255 & 255 & 255 & 255 & 255 & 255 & 255 \\
\hline FT-fuels & $\mathrm{MW}_{\mathrm{FT}}$ & - & - & - & - & - & 458 & 458 & 458 & 458 \\
\hline CAPEX & $\mathrm{M} €$ & - & 266 & 328 & 264 & 268 & 571 & 582 & 765 & 783 \\
\hline OPEX & $\mathrm{M} € / \mathrm{y}$ & - & 16 & 19 & 16 & 16 & 34 & 34 & 45 & 46 \\
\hline
\end{tabular}

a Natural gas used for the production of steam, electricity and/or hydrogen.

b Excess heat in the gasification train is used for the production of steam.

c The waste gases coming from the gasification process are combusted in a newly built steam turbine to produce electricity.

sub-routes and all sub-routes can be implemented without CCS (vent) and with CCS. The key input data of the eight BIG sub-routes were based on process simulations developed by Meerman et al. in the AspenPlus ${ }^{\circledast}$ software $[42,43]$ and adapted for this specific refinery case (see Table 5). We assumed the BIG technology to become available in the medium term and to have an economic lifetime of 20 years.

3.3.3.2. Fast pyrolysis. The second biomass route is the production of pyrolysis oil from biomass and its upgrading to infrastructure-ready gasoline and diesel. A typical process for fast pyrolysis oil production comprises several steps: drying of feedstock (pre-treatment), thermal decomposition of the biomass (pyrolysis), upgrading of the pyrolysis oil using hydrogen gas (hydrotreating), and the separation of stable pyrolysis oil into different fractions, including gasoline and diesel (hydrocracking).

Due to potential issues with corrosion and limited availability of spare throughput capacity in existing refinery process units, the pyrolysis fuels were assumed to be produced in new processing units in addition to the refinery product output mix. For the same reason, the required hydrogen was assumed to be produced in a new SR due to possible capacity constraints in in situ SMR plants. We assumed that pyrolysis technology has an economic lifetime of 20 years and will become available in the medium term. The size of the pyrolysis train was limited to $1000 \mathrm{MW}_{\mathrm{HHV}}$ feed input. A PNNL study [44], which presents recent detailed and publicly available data coming from several US research institutes, was used for the analysis. The key data of the fast pyrolysis route can be found in Table 6 .

\subsection{Interactions among mitigation options}

The mitigation options EEM, CCS and biomass can interact in several ways. The EEMs affect each other's GHG reduction potential (see also Section 3.3.1). Likewise, fewer emissions can be reduced via CCS in the case where EEMs are already implemented. However, the interaction between EEMs and BIG is minor. Although the three $\mathrm{CO}_{2}$ capture technologies can be implemented side by side, this was found to be rather expensive in earlier research by the authors [45], due to of the high capital and operational costs per tonne $\mathrm{CO}_{2}$-eq avoided, and thus undesirable. Significant economies of scale can be achieved in both the combi CCS routes in which $\mathrm{CO}_{2}$ is captured from multiple sources, and in the BIG-combi sub-route in which multiple output products (steam, electricity, hydrogen and FT-fuels) are produced. CCS and BIG are
Table 6

Input data for fuel production via fast pyrolysis, hydrotreating and hydrocracking. All weights pertain to dry woody biomass. The abbreviations p-oil, bf and bm stand for pyrolysis oil, biofuel and biomass, respectively. Based on PNNL [44].

\begin{tabular}{|c|c|c|}
\hline & Unit & Quantity \\
\hline Energy content biomass & $\mathrm{MJ}_{\mathrm{LHV}} / \mathrm{kg}_{\mathrm{bm}}$ & 18.6 \\
\hline \multicolumn{3}{|l|}{ Fast pyrolysis } \\
\hline Capacity pyrolysis unit ${ }^{a}$ & $\mathrm{kt}_{\mathrm{bm}} / \mathrm{d}$ & $2.0^{\mathrm{a}}$ \\
\hline Mass yield & $\mathrm{t}$ p-oil/ $\mathrm{t}_{\mathrm{bm}}$ & 0.62 \\
\hline Overall energy yield & $\mathrm{GJ}_{\mathrm{bf}} / \mathrm{GJ}_{\mathrm{bm}}$ & 0.70 \\
\hline Energy content biofuel & $\mathrm{MJ}_{\mathrm{bf}} / \mathrm{L}_{\mathrm{bf}}$ & 32 \\
\hline Electricity & $\mathrm{MJ}_{\mathrm{e}} / \mathrm{L}_{\mathrm{bf}}$ & 1.2 \\
\hline Water & $\mathrm{L} / \mathrm{L}_{\mathrm{bf}}$ & 1.5 \\
\hline Natural gas & $\mathrm{MJ} / \mathrm{L}_{\mathrm{bf}}$ & 4.7 \\
\hline \multicolumn{3}{|l|}{ Costs } \\
\hline Process Plant Cost & $€ / \mathrm{L}_{\mathrm{bf}} / \mathrm{day}$ & 385 \\
\hline OPEX & $€ / \mathrm{L}_{\mathrm{bf}}$ & 0.2 \\
\hline
\end{tabular}

a The reference size of the pyrolysis unit was $2.0 \mathrm{kt} / \mathrm{d}$ of dry biomass. For $1000 \mathrm{MW}$ biomass input $(5.1 \mathrm{kt} / \mathrm{d})$, three pyrolysis units were assumed to be required.

complementary technologies that can deliver net negative emissions. BIG and pyrolysis can compete with respect to the production of green fuels.

\subsection{Sensitivity analysis}

The impact of the input parameter values was assessed by doing a sensitivity analysis. The parameters included in this analysis are: energy prices, annualized capital cost, grid electricity GHG emission factor, biomass supply chain GHG emissions, $\mathrm{CO}_{2}$ transport \& storage costs, process energy use, and NGCC(-CHP) efficiency. The variations in the input parameters are presented in Table 7 . The combined effect of the parameters on the results was assessed by calculating an extreme pessimistic and extreme optimistic case, in which all parameters are set at their least and most favorable values, respectively. The impact of the varied input parameters is indicated with error bars in the GHG reduction potential and avoidance costs. 
Table 7

Input parameters and ranges used for sensitivity analysis.

\begin{tabular}{|c|c|c|c|c|}
\hline & Unit & Medium value & Range for sensitivity analysis & References \\
\hline \multicolumn{5}{|l|}{ Generic } \\
\hline \multicolumn{5}{|l|}{ Industrial energy price 2025} \\
\hline Transport fuel ${ }^{\mathrm{a}}$ & $€ / \mathrm{GJ}_{\mathrm{LHV}}$ & 16 & $9-26$ & {$[2]$} \\
\hline Natural gas & $€ / \mathrm{GJ}_{\mathrm{LHV}}$ & 10 & $7-13$ & [2]; own estimations \\
\hline Electricity & $€ / \mathrm{GJ}_{\mathrm{e}}$ & 22 & $15-29$ & [70]; own estimations \\
\hline Steam (LHV) ${ }^{\mathrm{b}}$ & $€ / \mathrm{GJ}_{\mathrm{th}}$ & 12 & $8-15$ & Own value \\
\hline Torrefied wood pellets (TOPS) ${ }^{c}$ & $€ / \mathrm{GJ}_{\mathrm{LHV}}$ & 8.0 & $3.4-8.8$ & {$[42,71]$} \\
\hline Woody biomass for pyrolysis & $€ / \mathrm{GJ}_{\mathrm{LHV}}$ & 3.5 & $2.6-5.2$ & [44] \\
\hline \multicolumn{5}{|l|}{ Life cycle GHG emissions } \\
\hline Electricity grid production ${ }^{\mathrm{d}}$ & $\mathrm{kgCO}_{2}-\mathrm{eq} / \mathrm{GJ}_{\mathrm{e}}$ & 63 & $16-110$ & {$[73]$} \\
\hline Torrefied wood pellets (TOPS) & $\mathrm{kgCO}_{2}$-eq/GJ & 7.9 & $4.9-10.9$ & {$[74,75,97]$} \\
\hline Woody biomass for pyrolysis & $\mathrm{kgCO}_{2}-\mathrm{eq} / \mathrm{GJ}$ & 1.9 & $1.2-2.6$ & [77] \\
\hline CAPEX & & $-{ }^{e}$ & $\pm 30 \%$ for total annualized capital cost & {$[38]$} \\
\hline \multicolumn{5}{|l|}{ EEMs } \\
\hline Primary energy savings & $\mathrm{GJ} / \mathrm{y}$ & $-{ }^{e}$ & $\pm 30 \%$ & {$[98]$} \\
\hline \multicolumn{5}{|l|}{ CCS } \\
\hline Energy use $\mathrm{CO}_{2}$ capture & $\mathrm{GJ} / \mathrm{tCO}_{2}$ & $-{ }^{e}$ & $\pm 30 \%$ & {$[38]$} \\
\hline HP steam from waste heat of the SR & $\mathrm{GJ}_{\mathrm{th}} / \mathrm{tCO}_{2}$ & 25 & $20-30$ & Own values \\
\hline Max. NGCC efficiency (LHV) & $\%$ & $-{ }^{f}$ & $45-60$ & Own values \\
\hline Max. NGCC-CHP efficiency (LHV) & $\%$ & 90 & $75-100$ & Own values \\
\hline $\mathrm{CO}_{2}$ transport \& storage costs & $€ / \mathrm{tCO}_{2}$ & 16 & $7-26^{g}$ & {$[61,62]$} \\
\hline \multicolumn{5}{|l|}{ BIG } \\
\hline Energy efficiency & $\%$-pt & $-{ }^{\mathrm{h}}$ & $+15 /-5^{\mathrm{i}}$ & Own values \\
\hline \multicolumn{5}{|l|}{ Pyrolysis } \\
\hline Energy efficiency & $\%$ & 70 & $62-72$ & [44] \\
\hline
\end{tabular}

a The transport fuel price was based on projected developments in the crude oil price. Considering the large uncertainty in the crude oil price, which is driven by

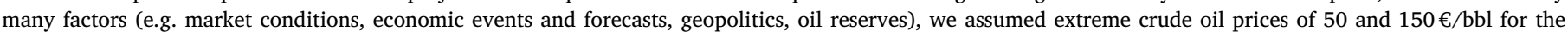
sensitivity analysis; this translates to a transport fuel price of 9 and $26 € / \mathrm{GJ}_{\mathrm{LHV}}$, respectively. A similar price range was used for green transport fuels.

$\mathrm{b}$ The steam production costs were varied with the range in natural gas price.

c The method of Meerman et al. [42] was adopted to derive the TOPS price range (see also footnote e in Table 1 ). A high biomass pellet price of $8.8 €_{2012} / \mathrm{GJ}_{\mathrm{LHV}}$

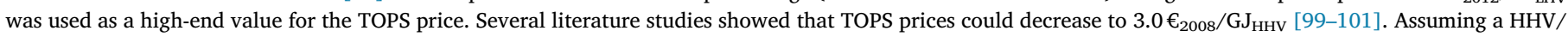
LHV ratio of 1.06 for TOPS [43], this translates to $3.4 €_{2012} / \mathrm{GJ}_{\mathrm{LHV}}$, which was used as a low-end value for the TOPS price.

d A large uncertainty range of $\pm 75 \%$ was assumed to examine the impact on the GHG reduction potential.

e The medium value for the CAPEX and energy use differs for each technology and is therefore not indicated in the Table. The $\pm 30 \%$ range was based on typical

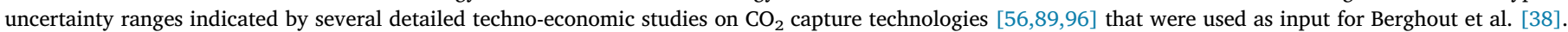
Ranges of $\pm 30 \%$ were used for EEM, BIG and pyrolysis as well.

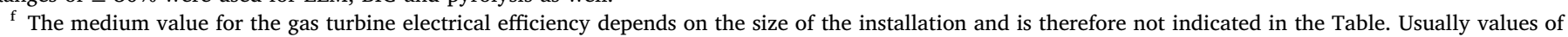
50-55\% were calculated (see [80]).

$\mathrm{g}$ The presented cost range is mainly due to the various transport conditions (on- and offshore pipelines, volumes (2.5-20 Mt/y) and distances (180-1500 km)) as

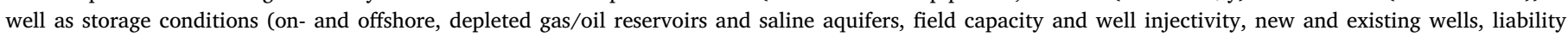
transfer costs), and to a lesser degree to uncertainty in the cost elements [61,62].

$\mathrm{h}$ The TOPS input energy demand differs for each BIG sub-route and is therefore not indicated in the Table.

i An asymmetric uncertainty range $(+15 \% /-5 \%)$ was used for the BIG technology, as the positive error, partly due to the improvement potential in the BIG conversion efficiency for the medium term compared to the year 2012, is expected to be larger than the negative error.

\section{Results}

\subsection{Mitigation options}

Fig. 3 presents the GHG reduction potential and GHG avoidance cost of all individual mitigation options (hereafter called 'sub-routes') and of several sub-routes together (hereafter called 'combined sub-routes'). ${ }^{5}$ These GHG reduction potentials were based on the 2012 base case emissions of $4.1 \mathrm{MtCO}_{2}$-eq. However, as shown by the black bars in the figure, base case emissions may increase to $4.8 \mathrm{MtCO}_{2}-\mathrm{eq} / \mathrm{y}$ in the medium term as a result of the higher $\mathrm{MD} / \mathrm{G}$ ratio, and possibly to $5.9 \mathrm{MtCO}_{2}$-eq/y due to stricter regulations on product quality change

\footnotetext{
${ }^{5}$ In this section, a clear distinction is made between 'sub-routes', like 'Energy management \& control' or 'post-combustion capture from gas turbines', and 'combined sub-routes', like all post-combustion sub-routes together, to avoid confusion. Combined sub-routes were explored to examine possible interactions between different sub-routes.
}

(see Section 3.2). If these higher projected emissions were taken as basis for the analysis, the absolute reduction potentials for the medium term would have been higher. Most error bars of the $\mathrm{CO}_{2}$ avoidance costs are asymmetric due to uneven uncertainty ranges of the input parameters, and the fact that optimistic changes in input parameters can have a larger effect on the avoidance costs than pessimistic changes, and vice versa.

In the EEM combi sub-route with short and long term EEMs GHG emissions are reduced by $1.1 \mathrm{MtCO}_{2}$-eq/y, which corresponds to $28 \%$ of the base case emissions, and avoidance cost is $-133 € / \mathrm{tCO}_{2}$-eq on average. The EEM with the lowest avoidance cost is improved energy management \& control, followed by the optimization of the steam distribution systems and fouling mitigation (medium values: -172 to $-166 € / \mathrm{tCO}_{2}$-eq). As the avoidance costs are well below the $\mathrm{CO}_{2}$ price range for the short-medium term $\left(20-75 € / \mathrm{tCO}_{2}\right)$, the EEMs can be considered non-regret options. 


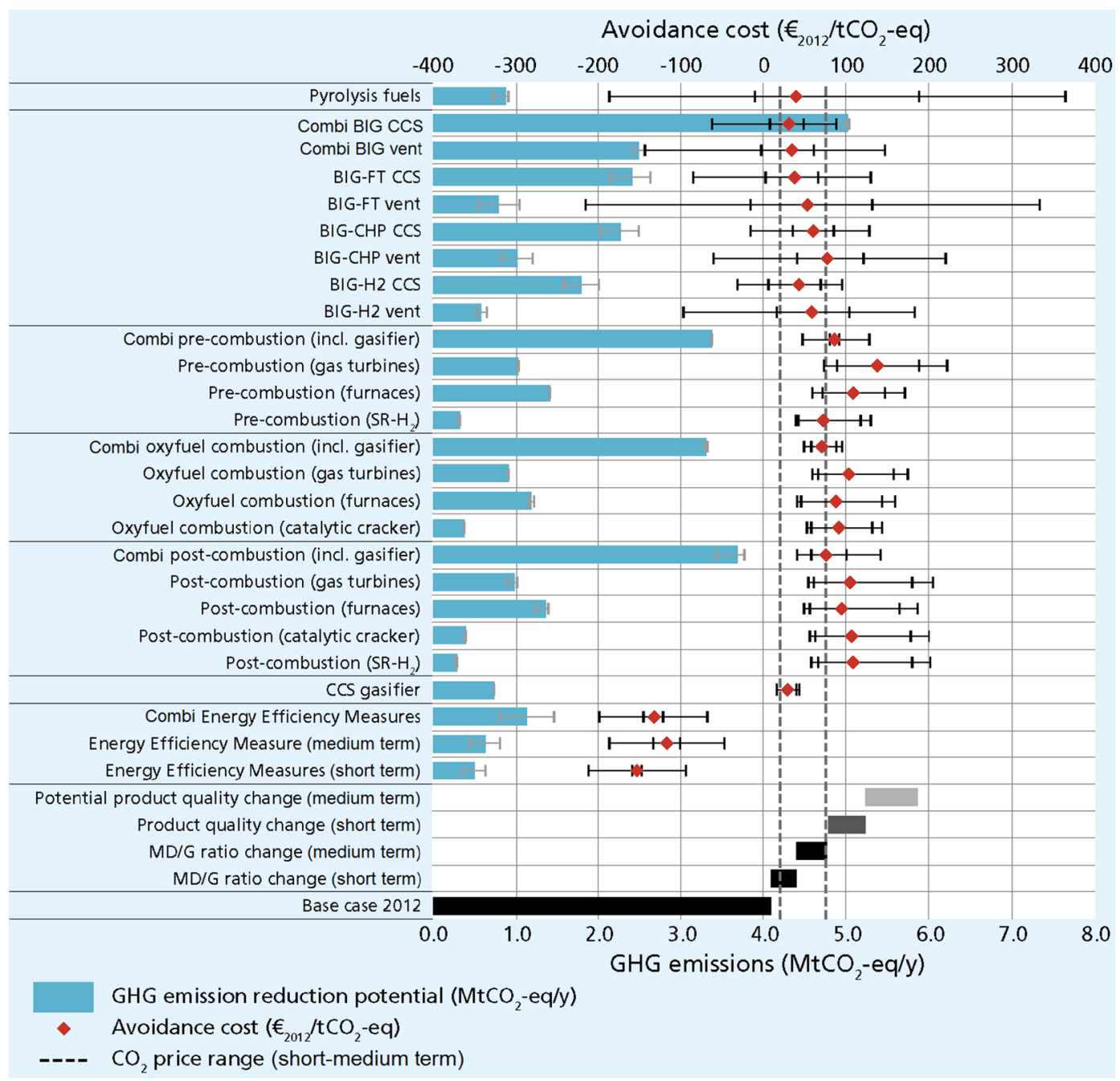

Fig. 3. $\mathrm{CO}_{2}$ emission projections, GHG reduction potential and GHG avoidance cost of the sub-routes. The top blue bar and diamond in each main route represent the GHG reduction potential and average avoidance cost of all sub-routes together (also called the combi sub-routes). The error bars show the sensitivity of the results to the uncertainty ranges in the input parameters. Whereas the outer error bar for the avoidance costs presents the sensitivity of the results to all parameter variations, the inner error bar excludes variations in natural gas, transport fuel, woody biomass and TOPS prices. For $\mathrm{CO}_{2}$ capture from the in situ gasifier, it was cheaper to purchase electricity from the grid rather than installing a new CHP unit. For $\mathrm{CO}_{2}$ capture from the CHP unit, post-combustion is also used in the pre-combustion route resulting in lower costs than the use of pre-combustion capture.

The CCS routes show significantly higher GHG reduction potentials than the EEMs, with up to $90 \%$ of the base case emissions (3.7 $\mathrm{MtCO}_{2^{-}}$ eq/y) in the post-combustion route. In the other CCS routes less $\mathrm{CO}_{2}$ is avoided, because $\mathrm{CO}_{2}$ cannot be captured from the SR in the oxyfuel route and from the catalytic cracker in the pre-combustion route. $\mathrm{CO}_{2}$ capture from the in situ gasifier shows the lowest avoidance costs (29€/ $\mathrm{tCO}_{2}$-eq) as this process involves only the compression of $\mathrm{CO}_{2}$ before it is sent off for transport and storage. ${ }^{6}$ For all three CCS-combi routes in which $\mathrm{CO}_{2}$ is captured from all suitable refinery emission sources, the average avoidance cost is lower than when $\mathrm{CO}_{2}$ is captured from individual $\mathrm{CO}_{2}$ emission sources, due to economies of scale and the low costs for $\mathrm{CO}_{2}$ capture from the in situ gasifier. Costs of the oxyfuel and post-combustion capture combi sub-routes are the lowest with $76 €$ / $\mathrm{tCO}_{2}$-eq and $71 € / \mathrm{tCO}_{2}$-eq), respectively. However, the costs for the post-combustion combi sub-route increase to $91 € / \mathrm{tCO}_{2}$-eq when rev-

\footnotetext{
${ }^{6}$ For $\mathrm{CO}_{2}$ capture from the gasifier, electricity was purchased from the grid rather than generated in a newly installed CHP unit as this showed lower costs.
}

enues and avoided GHG emissions related to export of excess electricity production are excluded ${ }^{7}$ from the analysis.

The individual BIG vent and BIG CCS sub-routes (only steam/electricity, $\mathrm{H}_{2}$ or FT-fuel production) display GHG reduction potentials of 0.6-1.0 $\mathrm{MtCO}_{2}$-eq (14-25\%) and 1.8-2.4 $\mathrm{MtCO}_{2}$-eq (44-59\%), respectively. The low avoidance costs are mainly because the natural gas price (medium value NG price: $10 € / G J$ ) is higher than the TOPS price (medium value: $8.0 € / G J$ ), which has a dampening effect on the avoidance costs. The larger uncertainty in the values of the BIG vent compared to BIG CCS sub-routes is mainly caused by the lower amount of avoided GHG emissions, which makes these sub-routes more sensitive to changes in key input parameters, particularly energy prices. The BIG-combi CCS sub-route shows a very large GHG reduction potential ( $5.0 \mathrm{MtCO}_{2}$-eq; $123 \%$ reduction compared to 2012 base case emissions),

\footnotetext{
${ }^{7}$ When excluding credits for electricity export, the monetary value and (indirect) $\mathrm{CO}_{2}$ emissions of both the exported electricity and natural gas related to this electricity, which was determined on an exergy basis (electricity: 1; heat: 0.28) (see Table 1), were subtracted from the total emissions and costs.
} 
which can be achieved at avoidance costs of $31 € / \mathrm{tCO}_{2}$-eq. These net negative emissions are the sum of the avoided fossil fuels (crude oil as feed in refinery and natural gas both as feed and fuel for $\mathrm{H}_{2}$ production), $\mathrm{CO}_{2}$ captured from the biomass, and $\mathrm{CO}_{2}$ credits for export of excess electricity produced.

The pyrolysis route shows a GHG reduction potential of $0.9 \mathrm{MtCO}_{2^{-}}$ eq $(21 \%)$ and avoidance costs of $39 € / \mathrm{tCO}_{2}$-eq. The small GHG reduction potential is a direct result of the 'limited' size assumed for the pyrolysis train (1000 $\mathrm{MW}_{\mathrm{HHV}}$ feed input), which enabled us to compare the performance with the BIG-FT sub-route. The results show that avoidance costs and GHG reduction potential of the pyrolysis and BIGFT CCS sub-route are comparable.

The large uncertainty ranges, especially for the BIG vent and pyrolysis routes, are due to stacking of (independent) uncertainties in the underlying input parameters. The high uncertainties for the BIG vent and pyrolysis routes are mainly because these routes depend on both biomass and natural gas prices, whereas EEMs and CCS depend predominantly on either natural gas or electricity prices. As the uncertainty ranges are most likely normally distributed, the extreme values will be less likely than the medium values.

\subsection{Deployment pathways}

Four promising pathways were identified based on the performance of the individual mitigation options, the technological maturity of these options and their potential impact on the core refinery processes. In all

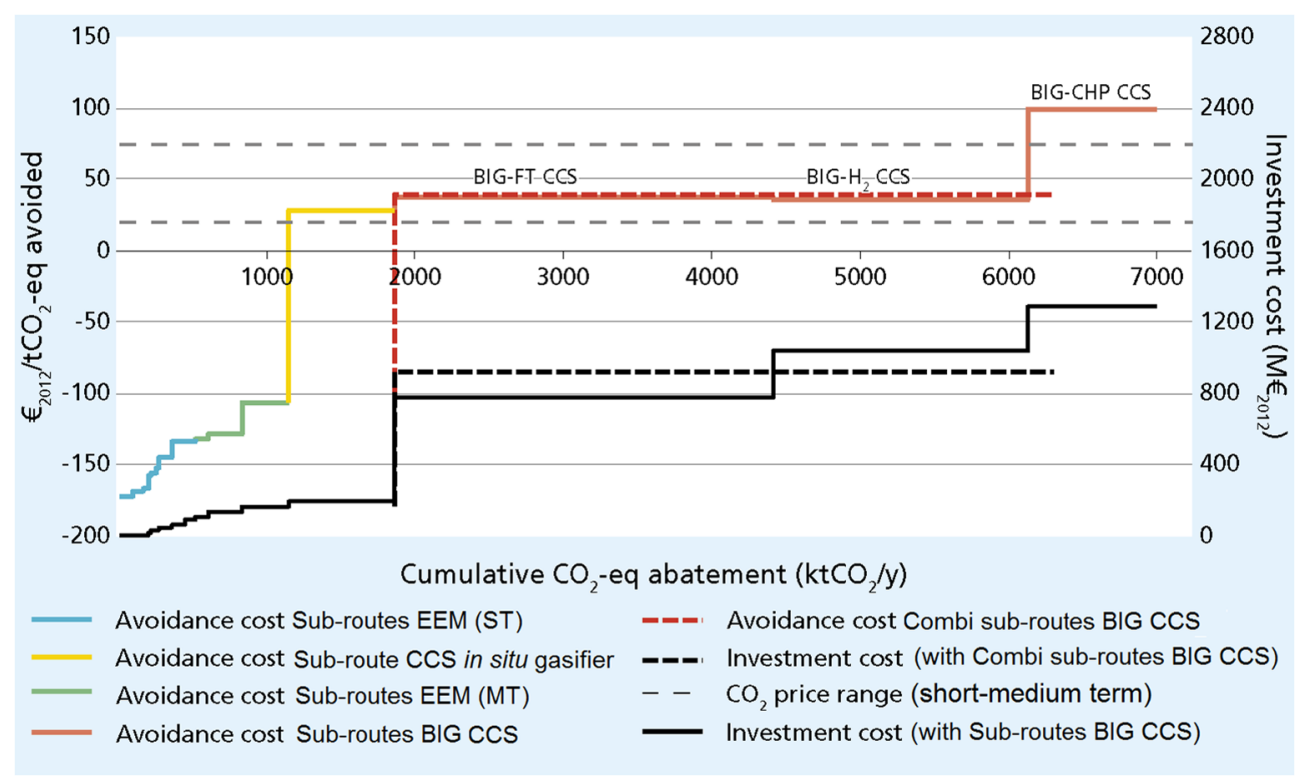

Fig. 4. Marginal abatement cost curve for pathway EEM-BIG-CCS.

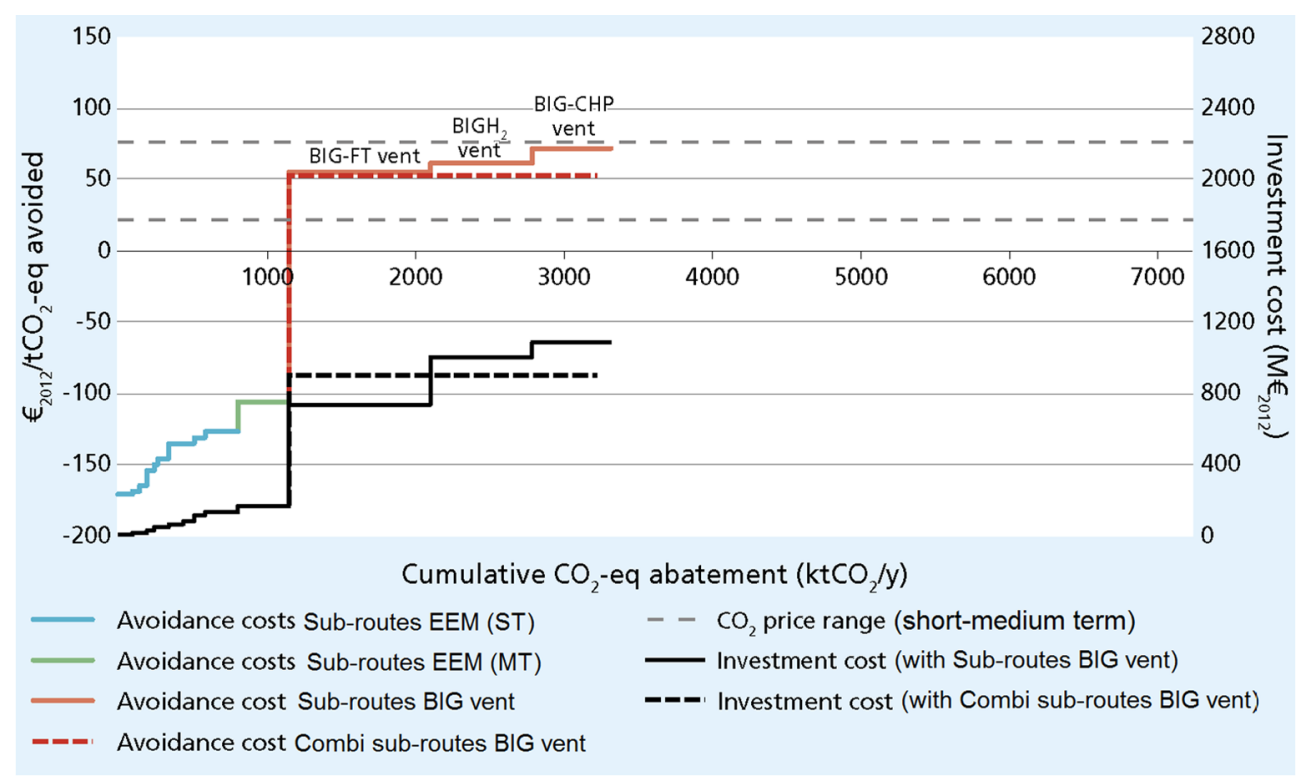

Fig. 5. Marginal abatement cost curve for pathway EEM-BIG-vent. 


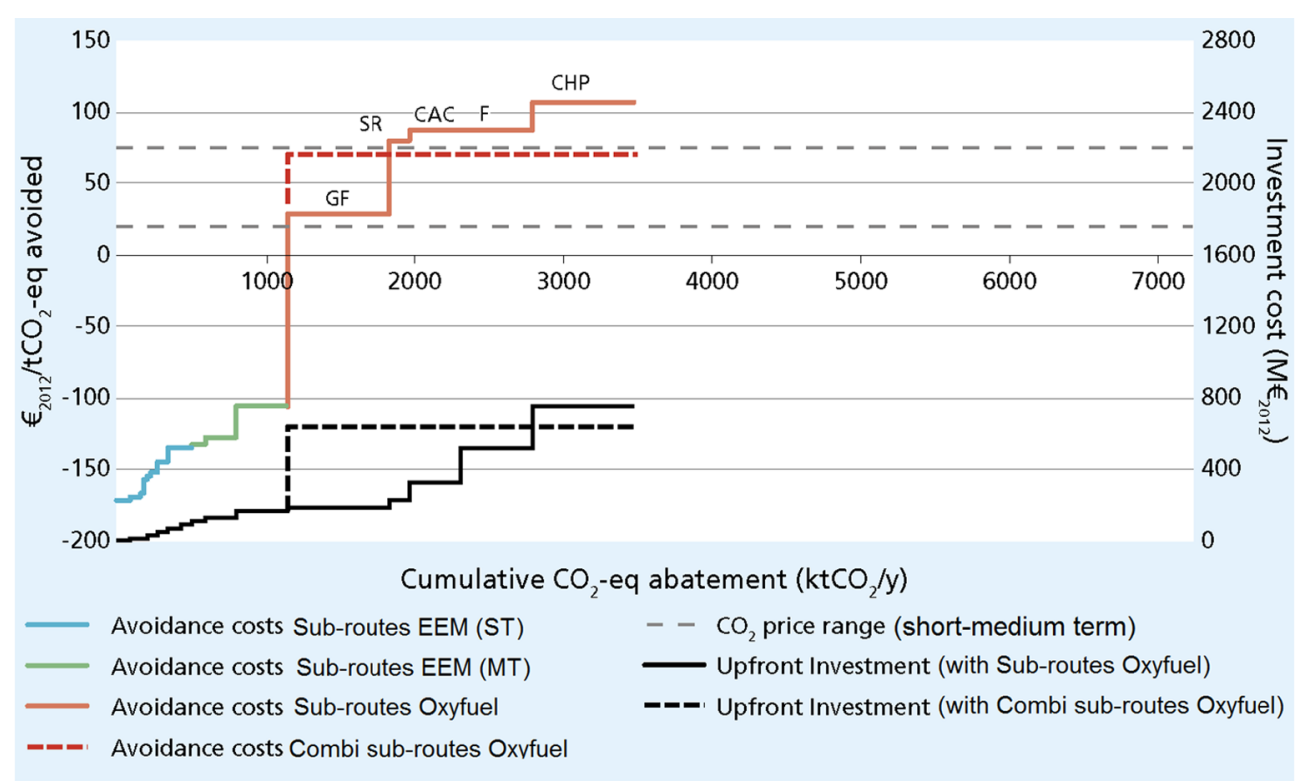

Fig. 6. Marginal abatement cost curve for pathway EEM-OXY. GF, SR, CAC, F and CHP stand for gasifier, steam reformer, catalytic cracker, furnaces and combined heat power, respectively.

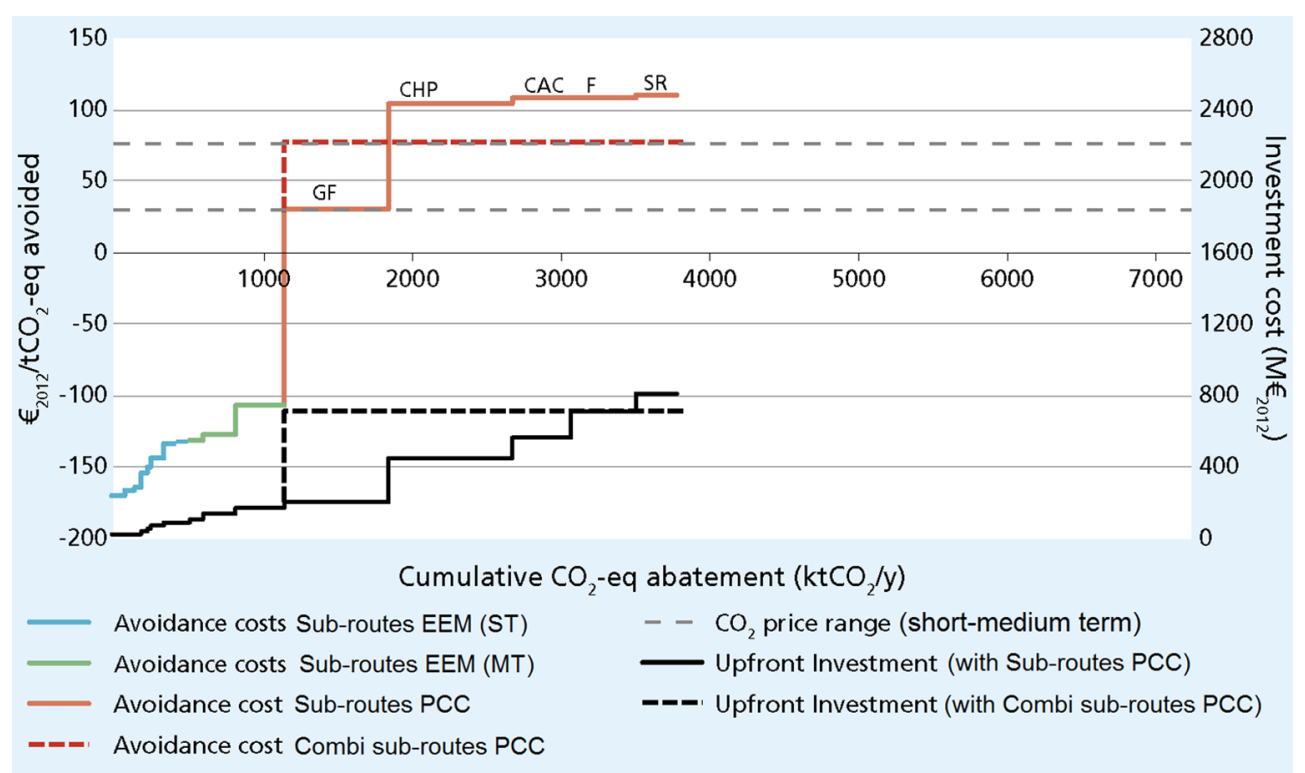

Fig. 7. Marginal abatement cost curve for pathway EEM-POST. GF, SR, CAC, F, CHP and PCC stand for gasifier, steam reformer, catalytic cracker, furnaces, combined heat power and post-combustion capture, respectively.

four pathways, EEMs are implemented first due to their negative avoidance costs. Albeit implementing EEMs first may create a lock-in of the current refinery infrastructure, fossil-based refined products will most likely continue to play a significant role up to the year 2030, thus ensuring an outlet for these products in the coming decades. The first pathway, EEM-BIG-CCS, has the lowest average avoidance cost and highest emission reductions, due to the favorable performance of the BIG-CCS option. BIG vent and CCS were also considered separately in three other pathways to explore the possibility that the other technology, CCS or biomass gasification, would not become available in the future (on time) (lower risk pathways). The CCS technologies chosen are oxyfuel combustion (lowest cost) and post-combustion (most technologically mature and lowest potential impact on core refinery processes). For the biomass utilization pathway, BIG was chosen over pyrolysis due to the large uncertainty in the input parameters of the latter technology. Furthermore, the BIG options are complementary and provide opportunities for synergies.

To summarize, the following four deployment pathways were investigated: 
Table 8

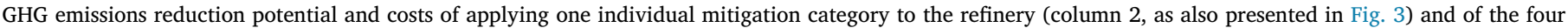

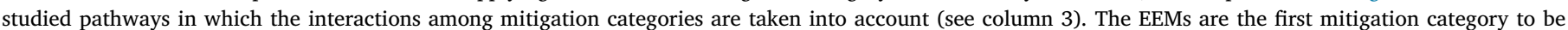

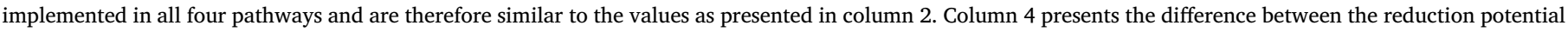

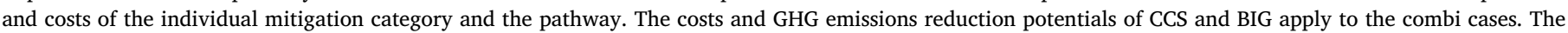
abbreviation \%pt stands for percentage point.

$\begin{array}{ll}\text { NO INTERACTION } & \text { WITH INTERACTION } \\ \text { Individual mitigation category } & \text { Pathway }\end{array}$

Unit

\begin{tabular}{|c|c|c|c|c|c|c|c|c|}
\hline Pathway EEM-BIG-CCS & & EEM & BIG CCS & EEM & $\begin{array}{l}\text { CCS in situ gasifier + BIG } \\
\text { CCS }\end{array}$ & Total & BIG CCS & Total \\
\hline GHG emissions avoided & $\mathrm{MtCO}_{2}-\mathrm{eq} / \mathrm{y}$ & 1.1 & 5.0 & 1.1 & 5.2 & 6.3 & 0.1 & 1.3 \\
\hline Reduction base case 2012 & $\%$ & $28 \%$ & $140 \%$ & $28 \%$ & $126 \%$ & $154 \%$ & $-14 \% \mathrm{pt}$ & $14 \% \mathrm{pt}$ \\
\hline Upfront investment cost & $\cdot 10^{3} \mathrm{M} €$ & 0.2 & 0.8 & 0.2 & 0.8 & 0.9 & 0.0 & 0.2 \\
\hline Average GHG avoidance cost & $€ / \mathrm{tCO}_{2}$-eq & -133 & 31 & -133 & 39 & 12 & 8 & -19 \\
\hline Pathway EEM-BIG-vent & & EEM & BIG vent & EEM & BIG vent & Total & BIG vent & Total \\
\hline GHG emissions avoided & $\mathrm{MtCO}_{2}-\mathrm{eq} / \mathrm{y}$ & 1.1 & 2.5 & 1.1 & 2.1 & 3.2 & -0.4 & 0.7 \\
\hline Reduction base case 2012 & $\%$ & $28 \%$ & $61 \%$ & $28 \%$ & $51 \%$ & $79 \%$ & $-10 \%$ pt & $18 \%$ pt \\
\hline Upfront investment cost & $\cdot 10^{3} \mathrm{M} €$ & 0.2 & 0.8 & 0.2 & 0.7 & 0.9 & 0.0 & 0.1 \\
\hline Average GHG avoidance cost & $€ / \mathrm{tCO}_{2}$-eq & -133 & 34 & -133 & 52 & -13 & 18 & -48 \\
\hline Pathway EEM-OXY & & EEM & Oxyfuel & EEM & Oxyfuel & Total & Oxyfuel & Total \\
\hline GHG emissions avoided & $\mathrm{MtCO}_{2}-\mathrm{eq} / \mathrm{y}$ & 1.1 & 3.3 & 1.1 & 2.3 & 3.5 & -1.0 & 0.2 \\
\hline Reduction base case 2012 & $\%$ & $28 \%$ & $81 \%$ & $28 \%$ & $57 \%$ & $85 \%$ & $-24 \% p t$ & $4 \% p t$ \\
\hline Upfront investment cost & $\cdot 10^{3} \mathrm{M} €$ & 0.2 & 0.8 & 0.2 & 0.6 & 0.7 & -0.2 & 0.0 \\
\hline Average GHG avoidance cost & $€ / \mathrm{tCO}_{2}$-eq & -133 & 71 & -133 & 71 & 4 & 0 & -67 \\
\hline Pathway EEM-POST & & EEM & Post-combustion & EEM & Post-combustion & Total & Post-combustion & Total \\
\hline GHG emissions avoided & $\mathrm{MtCO}_{2}-\mathrm{eq} / \mathrm{y}$ & 1.1 & 3.7 & 1.1 & 2.6 & 3.8 & -1.0 & 0.1 \\
\hline Reduction base case 2012 & $\%$ & $28 \%$ & $90 \%$ & $28 \%$ & $64 \%$ & $92 \%$ & $-26 \%$ pt & $2 \% \mathrm{pt}$ \\
\hline Upfront investment cost & $\cdot 10^{3} \mathrm{M} €$ & 0.2 & 0.7 & 0.2 & 0.6 & 0.8 & 0.0 & 0.1 \\
\hline Average GHG avoidance cost & $€ / \mathrm{tCO}_{2}$-eq & -133 & 76 & -133 & 77 & 14 & 1 & -62 \\
\hline
\end{tabular}

COMPARISON

Difference pathway with individual

mitigation category
- Pathway EEM-BIG-CCS - Consecutive implementation of EEMs and BIG CCS. ${ }^{8}$

- Pathway EEM-BIG-vent - Consecutive implementation of EEMs (short and medium term) and BIG vent;

- Pathway EEM-OXY - the consecutive implementation of EEMs (short and medium term) and the CCS technology with the lowest GHG avoidance cost (i.e. oxyfuel combustion);

- Pathway EEM-POST - Consecutive implementation of EEMs (short and medium term) and the CCS technology with the lowest impact on the core refinery processes (i.e. add-on technology post-combustion capture);

Marginal cost abatement curves were constructed for all four pathways, starting with the route with the lowest avoidance cost (see Figs. 4-7). These curves show the medium values of the computed GHG reduction potentials and marginal avoidance costs, i.e. the costs per tonne of $\mathrm{CO}_{2}$-eq avoided of the last implemented sub-route. The colored lines denote the marginal avoidance costs of the individual sub-routes, whereas the black lines represent the cumulative upfront investment costs. In all pathways, the abatement curves are similar for the deployment of the EEMs (blue and green lines). The dashed red lines represent the avoidance cost of the combined sub-routes, whereas the dashed black lines show the total cumulative upfront investment cost of the EEMs and combined cases. An overview of the results on the pathways and the combined sub-routes is presented in Table 8.

Pathways EEM-BIG-CCS and EEM-BIG-vent show GHG reduction potentials of $6.3 \mathrm{MtCO}_{2}$-eq/y (154\%, i.e. net negative emissions) and $3.2 \mathrm{MtCO}_{2}-\mathrm{eq} / \mathrm{y}$ (79\%), respectively. When comparing the GHG reduction potentials of the pathways with the projected refinery $\mathrm{CO}_{2}$ emissions in 2030, the reduction potentials are reduced to 108\% (EEMBIG-CCS) and 55\% (EEM-BIG-vent), respectively. Compared to the CCS routes, the EEMs and BIG routes reduce each other's emissions

\footnotetext{
${ }^{8}$ Low-cost $\mathrm{CO}_{2}$ capture from the in situ gasifier is included in this pathway.
}

reduction potential to a smaller extent (BIG CCS: $-14 \%$ pt; BIG vent: $-10 \% \mathrm{pt}$ ), because most EEMs are heat related and do not interact with BIG (see Table 8). The EEMs interacting with the BIG-CHP sub-route are energy management \& control, motors \& pumps and steam distribution system. These EEMs reduce primary energy input of the gas turbines/ CHP's with $30 \%$, which decreases the mitigation potential of the BIGCHP sub-route. Similarly, the BIG- $\mathrm{H}_{2}$ sub-route interacts with the EEM hydrogen management \& recovery, which lowers the natural gas input of the hydrogen production process by $2 \%{ }^{9}$; this leaves a smaller reduction potential for the BIG technology. ${ }^{10}$ The reduction in average avoidance costs of the pathway compared to applying only BIG (EEMBIG-CCS: $-19 € / \mathrm{tCO}_{2}$-eq; EEM-BIG-vent: $-48 € / \mathrm{tCO}_{2}$-eq) is not as large as for the CCS pathways, but still considerable. However, the uncertainties in average avoidance costs for both pathways (EEM-BIGCCS: -93 to $81 € / \mathrm{tCO}_{2}$-eq; EEM-BIG-vent: -180 to $100 € / \mathrm{tCO}_{2}$-eq) are relatively high, mainly due to their high dependence on energy prices. The marginal avoidance costs of the combined sub-routes (dashed red and black lines) are lower than for most individual BIG sub-routes (solid red and black lines), and are around the upper end $\left(75 € / \mathrm{tCO}_{2}\right)$ of the $\mathrm{CO}_{2}$ price range. The difference in the GHG reduction potential of the BIG-combi CCS sub-route $\left(6.3 \mathrm{MtCO}_{2}-\mathrm{eq} / \mathrm{y}\right)$ and individual BIG subroutes $\left(7.0 \mathrm{MtCO}_{2}-\mathrm{eq} / \mathrm{y}\right)$ in the EEM-BIG-CCS pathway is because of the lower amount of $\mathrm{CO}_{2}$ captured in the combi sub-route. ${ }^{11}$ The GHG

\footnotetext{
${ }^{9}$ In reality, the interaction between the EEMs hydrogen management \& recovery and the BIG- $\mathrm{H}_{2}$ sub-route will be smaller as not all the energy savings are related to the SR unit, but also to the hydrogen distribution system, which does not show any interactions with the $\mathrm{BIG}-\mathrm{H}_{2}$ sub-route.

${ }^{10}$ It was assumed that the EEM turbine pre-coupling, which uses the exhaust gas of a newly built gas turbine to supply heat to the in situ SR furnace, can be used together with the BIG- $\mathrm{H}_{2}$ sub-route as well without any interaction between both sub-routes.

${ }^{11}$ In the BIG-FT CCS and BIG-combi CCS facilities, the $\mathrm{CO}_{2}$ capture unit is placed after the sour WGS and AGR units. However, the syngas needs to be further shifted in a sweet WGS unit for the production of hydrogen, power and
} 
reduction potential of the pathway with the BIG-CCS combi sub-route could be enhanced to $7.0 \mathrm{MtCO}_{2}-\mathrm{eq} / \mathrm{y}$ as well by designing the BIG facility differently, which would result in slightly higher avoidance costs. However this option was not examined in this study.

The total GHG reduction potentials of pathways EEM-OXY and EEMPOST are $3.5 \mathrm{MtCO}_{2}-\mathrm{eq} / \mathrm{y}(85 \%)$ and $3.8 \mathrm{MtCO}_{2}$-eq/y (92\%), respectively. When comparing the GHG reduction potentials to the projected refinery $\mathrm{CO}_{2}$ emissions in 2030, the potentials are reduced to 59\% (EEM-OXY) and 64\% (EEM-POST). After the EEMs, pathways EEM-OXY and EEM-POST both start with $\mathrm{CO}_{2}$ capture from the in situ gasifier $\left(30 € / \mathrm{tCO}_{2}\right.$-eq). Although $\mathrm{CO}_{2}$ capture from the high-pressure process gas of the in situ SR is not an oxyfuel technology, this sub-route was included in pathway EEM$\mathrm{OXY}$ - second point source from which $\mathrm{CO}_{2}$ is captured - to maximize emissions reductions. The EEMs and CCS routes show large interactions: the more emissions are reduced via EEM, the less emissions can be reduced via CCS. In pathways EEM-OXY and EEM-POST, 24\%pt and 26\%pt, respectively, are reduced less than when CCS is applied without EEMs (see Table 8 ). In total, only $4 \%$ pt and $2 \%$ pt emissions, respectively, are reduced more in the pathways than when only CCS is applied. Nevertheless, the average avoidance costs of the entire pathways are substantially lower (EEMOXY: $-67 € / \mathrm{tCO}_{2}$-eq; EEM-POST: $-62 € / \mathrm{tCO}_{2}$-eq) than when applying only CCS due to the negative avoidance cost of the EEM. The marginal avoidance costs of the combined CCS sub-routes (dashed red lines) are lower than for most individual CCS sub-routes (solid red lines), mainly due to economies of scale of the capture equipment (and CHP plants).

Under full deployment, the cumulative upfront investment costs (dashed black lines) for the BIG pathways (0.9 billion euros) are higher than for EEM-OXY (0.7 billion euros) and EEM-POST (0.8 billion euros), but all four pathways show large uncertainty ranges of $\pm 0.3-0.4$ billion euros. Significant reductions in investment costs (0.1-0.3 billion euros) can be achieved by combining the CCS and BIG sub-routes in one combi CCS or BIG facility (solid black lines). Note that up to an emissions reduction of $45 \%$, the performance of the pathways is rather similar as they all start with EEMs and three of them follow with $\mathrm{CO}_{2}$ capture from the in situ gasifier. The avoidance costs of the pathways start to differ for higher emissions reductions. Although the average avoidance cost of pathway EEM-BIG-CCS is higher than for EEM-OXY and EEM-BIGvent under full deployment, the average and marginal avoidance costs are lowest up to $6.1 \mathrm{MtCO}_{2} / \mathrm{y}$ avoided. However, next to the techno-economic performance, the feasibility of the pathways also depends on the availability of a sustainable biomass supply chain and/or a CCS infrastructure as well as the operator's willingness to use novel technologies and (partly) abandon conventional operational processes. While the EEM-POST pathway involves relatively little change in the process units, the EEM-OXY pathway already requires more modifications. The BIG pathways are new concepts that completely differ from the core refinery process.

The method has proven useful to evaluate emissions reduction strategies in an industrial plant based on criteria such as GHG avoidance cost and GHG reduction potential. It can also be applied to other refineries and industries to identify such strategies, provided sufficient data on core processes is available. However, there is scope to improve the method and ensure that complete optimization of

\footnotetext{
(footnote continued)

steam. The $\mathrm{CO}_{2}$ formed during this reaction is not captured but vented to the atmosphere, resulting in a lower total amount of $\mathrm{CO}_{2}$ captured than in the individual BIG facilities together. This effect is reinforced by the fact that the syngas composition in the BIG-combi facility is geared towards a low $\mathrm{H}_{2}$ : $\mathrm{CO}$ ratio, which is necessary for the production of the FT fuels, but sub-optimal for the production of the hydrogen, power and steam. Consequently, more $\mathrm{CO}_{2}$ is created in the sweet WGS unit. This issue can be tackled by installing an additional $\mathrm{CO}_{2}$ capture unit after the sweet WGS unit, which would increase the avoidance cost of the BIG-combi CCS facility. This option would still be cheaper than implementing three individual BIG facilities separately.
}

emissions reduction pathways is achieved (see discussion section). Nevertheless, the results described above provide the refinery owner with information about the costs and GHG reduction potential of various mitigation options and deployment pathways, their ranking in terms of costs, their uncertainty and the key parameters affecting their performance. As a result, the demonstrated method in this study can help inform companies about the risks related to investments in certain technologies. The findings may also serve as valuable input for plant owners when doing detailed follow-up analyses with inhouse data to reduce uncertainties and refine the strategy. These evaluations should also consider drivers and barriers to low-carbon energy technology investment. For instance, a potential driver for the implementation of energy efficiency measures and use of biomass is lower sensitivity to fluctuations in fossil fuel prices. Conversely, investments in CCS may be hampered by high risks related to the availability of $\mathrm{CO}_{2}$ transport and storage infrastructure, public acceptance, the liability of geologically stored $\mathrm{CO}_{2}$.

\section{Discussion}

This section provides a comparison of the current results and findings of other studies (Section 5.1). Subsequently, the context and main limitations of the analysis are described (Section 5.2).

\subsection{Comparison with other studies}

The results were compared with findings in other studies by converting these findings to $€_{2012}$ (see Table 9). Note that other dissimilarities (i.e. input parameters and system boundaries) were not considered unless otherwise indicated. The total GHG reduction potential of the EEMs (20-36\%) was found to be in line with figures in other studies investigating the EEMs in US (20-30\%) and European $(20-50 \%)^{12}$ [46] refineries. However, lower values (10-20\%) were found by Szklo and Schaeffer [47]. This can be explained by: (i) the refinery-specific GHG reduction potential; and (ii) the exclusion of particular EEMs from their analysis due to unfavorable economics and/or practical issues. The avoidance cost ranges indicated by Ecofys [46] are similar to values found in this study; however, less optimistic values were reported by Holmgren and Sternhufvud [48]. A more detailed analysis into the costs and practical issues related to the EEMs in the studied refinery is therefore recommended. For the CCS cases, only the capture costs were compared, i.e. the costs for the $\mathrm{CO}_{2}$ transport and storage step were subtracted from the avoidance costs found in this study. The average avoidance costs for post-combustion capture are in agreement with Johansson et al. [17], but are lower than the findings of Kuramochi et al. [8], which can be partly explained by the large economic scale effects and high revenues for electricity sale in the current study. The lower emissions reductions in the other two studies are due to the fact that $\mathrm{CO}_{2}$ is not captured from the NGCC-CHP [8], or from all possible available point sources [17]. The emissions reductions and avoidance costs of the oxyfuel and precombustion cases are in line with other studies $[8,38]$. The avoidance costs of the BIG fuel case of Meerman et al. [18] are similar to our own findings.

Finally, due to lack of data on avoidance costs for pyrolysis fuel production with a similar production process as used in this study which was based on NREL data [44] - we compared the production costs of the first production step, the actual pyrolysis, which is similar in most studies covering fast pyrolysis. A generic equation presented by Bridgwater [49] was used to compute the bio-oil production cost ( $214 € / t$ bio-oil); this figure is in agreement with the cost found in this study $(206 € /$ t bio-oil).

\footnotetext{
${ }^{12}$ The high end value refers to old and inefficient refineries with an extremely high reduction potential.
} 
Table 9

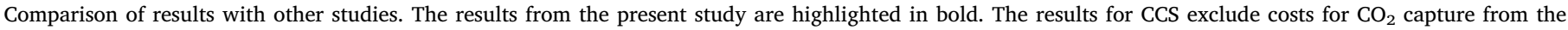
gasifier and $\mathrm{CO}_{2}$ transport \& storage for the sake of comparison.

\begin{tabular}{|c|c|c|c|c|c|}
\hline & GHG reduction potential (\%) & Geographical scope & Aggregation level & $\begin{array}{l}\text { Economics } \\
\left(€_{2012} / \mathrm{tCO}_{2} \text {-eq }\right)\end{array}$ & Reference \\
\hline \multirow[t]{6}{*}{ EEMs } & $20-36$ & NW Europe & Refinery & -226 to -33 & \\
\hline & $20-50$ & Europe & Sector & -150 to -102 & [46] \\
\hline & $20-30$ & US & Sector & N/A & [34] \\
\hline & $8-22$ & Sweden & Refinery & -98 to -27 & {$[48]$} \\
\hline & $10-20$ & Brazil & Sector & N/A & [47] \\
\hline & $5-20$ & Europe & Sector & N/A & [14] \\
\hline \multirow[t]{3}{*}{ Post-combustion capture (combined) } & $66-75^{a}$ & NW Europe & Refinery & $45-167$ & \\
\hline & $61-77^{\mathrm{a}}$ & Not indicated & Sector & $40-130^{\mathrm{b}}$ & [17] \\
\hline & 59 & Worldwide & Sector & $104-168$ & [8] \\
\hline \multirow[t]{2}{*}{ Oxyfuel combustion (combined) } & $62-63$ & NW Europe & Refinery & $53-106$ & \\
\hline & 77 & Worldwide & Sector & $52-81$ & {$[8]$} \\
\hline \multirow[t]{2}{*}{ Pre-combustion (combined) } & 65 & NW Europe & Refinery & 54-152 & \\
\hline & $64-82$ & Netherlands & Refinery & $87-90^{c}$ & {$[38]$} \\
\hline \multirow[t]{2}{*}{ BIG-FT vent } & 11-25 & NW Europe & Refinery & $64-123^{\mathrm{d}}$ & \\
\hline & N/A & NW Europe & Plant & $82-137$ & [18] \\
\hline \multirow[t]{2}{*}{ BIG-FT CCS } & $48-60$ & NW Europe & Refinery & $41-65$ & \\
\hline & N/A & NW Europe & Plant & $38-66$ & [18] \\
\hline
\end{tabular}

a The GHG reduction potential of this study and Johansson et al. [17] include $\mathrm{CO}_{2}$ capture from the NGCC-CHP, whereas this is not included in Kuramochi et al. [8].

b The range only covers the cases with an NGCC-CHP as energy plant for post-combustion capture as presented in Johansson et al. [17].

c These are medium values; the sensitivity of these results were explored by doing a sensitivity analysis for each input parameter. However, no cumulative cost uncertainty range is available.

${ }^{\mathrm{d}}$ We recalculated our values by using the natural gas price $(6 € / \mathrm{GJ})$, TOPS price $(6.7 € / \mathrm{GJ})$ and crude oil price (73€/bbl) of Meerman et al. [18].

\subsection{Discussion of method, data quality and results}

Four main points of discussion have been identified.

First, this study aimed to develop a method to identify emissions reduction strategies. Although this method has proven useful, further efforts are required to achieve complete optimization. Several aspects should be considered in further detail, such as biomass supply chains, CCS infrastructure, age and decommission of existing capital stock and the willingness of industries to use novel technologies. Furthermore, the calculations on the industrial plant need to be better linked to the temporal dynamics of the energy systems in which it is embedded, including changes in industrial demand, energy prices and the availability of hydrogen. A more sophisticated sensitivity analysis with a better characterization of uncertainty ranges of the input parameters would improve the quality of the results and be useful input for strategic planning [50].

The second issue concerns paucity of data and assumptions on refinery processes and mitigation options. Limited information on core refinery processes made it necessary to make assumptions on the refinery hydrogen production output as well as on capacity factors and efficiencies of process units. However, the effect of these assumptions on the final results is expected to be minor. For the same reason, the pyrolysis and FT-fuel production routes were examined as additional output products (processed in new equipment) rather than substitutes of fossil gasoline and diesel, which were kept constant in the analysis. For the pyrolysis fuel route, utilizing existing process units could result in significantly lower avoidance cost [51]. Also, heat integration of the FT-process in the refinery could enhance the GHG reduction potential and economic performance of this mitigation option [52]. However, at the same time, the GHG reduction potential and avoidance cost of several EEMs would deteriorate, once green fuel production replaces part of the crude oil throughput, due to a lower fossil energy saving potential. Follow-up research is needed to determine at which level of replacement implementing EEMs remains beneficial, and when it is better to omit EEMs and implement the green fuel technologies directly. For the pre-combustion route, using an Autothermal Reformer (ATR) with $\mathrm{CO}_{2}$ capture is probably economically preferable over a SR with $\mathrm{CO}_{2}$ capture from both the high-pressure process gas and fuel gas stream [53,54]. More detailed and reliable data on this mitigation option is needed. Also, possible improvements in post-combustion solvents, and the oxygen and hydrogen production efficiency could lower the avoidance costs of the capture technologies. Several mitigation options (e.g. low-grade WH utilization for district heating and geothermal energy) were not investigated in this study, but could be promising from a GHG reduction perspective. Golombok and Beintema [55] report that under favorable conditions, utilizing geothermal energy for process heating could have a high financial reward for a large scale refinery, but risks are currently too high and further research is required before this process can become economically viable. A followup study for the case refinery would require more detailed plant data as well as a total site analysis to assess the energy recovery by the different site processes.

Third, the cost estimates of the mitigation options involve some degree of uncertainty. Although key techno-economic data underlying the mitigation options stem from studies covering multiple data sources, these figures are not tailored to the specific configuration of the case refinery. Due to the lack of detailed data on investment costs for EEMs, costs were derived using the simple payback period equation. More reliable and detailed data is needed on investment costs for EEMs to eliminate the large uncertainty in the avoidance costs. All the input cost data pertain to technologies that are commercially mature, assuming the costs of advanced EEMs, CCS and biomass routes will decline over time as a result of technological learning. Yet, this will depend strongly on the deployment of these technologies over the coming decades. Moreover, it should be noted that several factors affecting the practical feasibility and economic performance of the mitigation options have been neglected, such as the creation of space for new process equipment and biomass storage, (production loss due to) retrofit and lower process reliability. A rough calculation by the authors indicates that a storage dome with a $40 \mathrm{~m}$ diameter and $50 \mathrm{~m}$ height would be required to run the combined BIG facility for one week. ${ }^{13}$ Considering

\footnotetext{
${ }^{13}$ Calculation based on a calorific value of $19-23 \mathrm{MJ}_{\mathrm{LHV}} / \mathrm{kg}$ [4], a bulk TOPS density of $750-850 \mathrm{~kg} / \mathrm{m}^{3}$ [4], and a dome-shaped storage facility with a diameter of $63 \mathrm{~m}$, a height of $50 \mathrm{~m}$ and a volume of $110,000 \mathrm{~m}^{3}$ [7].
} 
the space availability on the case study refinery site this should be practically feasible. Furthermore, (part of the) biomass could be stored in river barges until unloading to the storage domes. Another issue not covered in this study is that hydrogen and/or FT-fuel production via TOPS gasification will result in lower O\&M expenses, but possibly also undepreciated capital costs for the conventional hydrogen and fuel production routes; these costs have not been taken into account. Lastly, limited water availability in the future could become a critical factor for water intensive technologies like post-combustion capture technology [56]. Although most of these neglected factors probably fall within the uncertainty ranges used for the most important input parameters underlying the analysis, more research is desirable to acquire more accurate results. The avoidance costs of some mitigation options (e.g. post-combustion capture) include economic revenues and avoided GHG emissions related to the sale of excess electricity or steam produced in the process. One might argue whether these revenues should be taken into account. When excluding electricity sale, the avoidance cost of the combined post- and pre-combustion mitigation options would increase from 40 to $142 € / \mathrm{tCO}_{2}$-eq (post) and $46-129 € / \mathrm{tCO}_{2}$-eq (pre) to $49-158 € / \mathrm{tCO}_{2}$-eq (post) and $50-144 € / \mathrm{tCO}_{2}$-eq (pre). For the BIG-FT vent and BIG-FT CCS cases, the medium avoidance costs rise with $54 €$ / $\mathrm{tCO}_{2}$-eq and $13 € / \mathrm{tCO}_{2}$-eq, respectively, when excluding electricity sale. Finally, it should be mentioned that the computed avoidance costs also depend on the regional scope. The high European natural gas price used in this study $(10 € / \mathrm{GJ})$ results in high avoidance costs for the precombustion route; in the US, however, pre-combustion (and postcombustion) capture will perform much better due to the lower natural gas price, which was on average around $3 € / G J$ in 2012 [57].

The fourth issue is related to the $\mathrm{CO}_{2}$ emission projections for the refinery. The results show significant increases in the business-as-usual $\mathrm{CO}_{2}$ emissions projections until $2030(16 \%)$ as a result of the increasing $\mathrm{MD} / \mathrm{G}$ ratio, assuming the heavy fuel oil and total refinery product output in the case refinery remain constant. These constant output levels are based on the premise that the studied complex refinery will be more likely to survive in the market at the expense of simple refineries, which require more investments in new processing capacity to accommodate for the changes in product demand. Furthermore, the increase in $\mathrm{CO}_{2}$ emissions was based on the CONCAWE model, for which several assumptions were made inter alia regarding the share of gasoline vehicles in the total EU car fleet (50\%) and the alternative fuel vehicles growth (15\% in the total car fleet) for 2030 [29]. The projected $\mathrm{CO}_{2}$ emissions are, therefore, uncertain. The GHG reduction potentials of the deployment pathways investigated in this study will be higher due to the projected increase in future $\mathrm{CO}_{2}$ emissions of the refinery. The combined effect of an increasing $\mathrm{MD} / \mathrm{G}$ ratio and stricter product quality regulations will increase the hydrogen demand, while the output of the catalytic cracker, which is geared towards a high gasoline output, will decline. As a result, the potential for $\mathrm{CO}_{2}$ capture from the high-concentration SR may be higher than indicated in the results, whereas the opposite is true for the catalytic cracker. This effect has not been examined in this study due to limited data available on the core refinery processes that is needed to allocate the future emission increases to the specific $\mathrm{CO}_{2}$ point sources.

\section{Conclusions}

The objective of the paper was to design and test an integrated method to assess deployment strategies for deep GHG emission reductions in industrial plants. Important steps in the method are the identification of GHG emission mitigation options and the design of pathways combining different options. Next, the techno-economic performance of both individual options and pathways are evaluated. The evaluation accounts for interactions between options such as the impact on each other's GHG reduction potential, cost synergies, economies of scale, and lock-in effects. The method was demonstrated for a large, complex petroleum refinery in North-West Europe with emissions of around $4.1 \mathrm{MtCO}_{2}$ in 2012.

For the short term, energy efficiency measures were identified as mitigation options, while for the medium term additional efficiency measures, carbon capture and storage (CCS), biomass gasification and fast pyrolysis of biomass were assessed. The efficiency measures were found to be non-regret options due to their negative GHG avoidance costs, but have a limited GHG reduction potential of $28 \%$ in total. Further GHG emission reductions can be realized in four identified pathways which all start with efficiency measures and are followed by either oxyfuel or postcombustion capture, or BIG with or without CCS. Under medium conditions, a pathway of efficiency measures and biomass gasification with CCS was found to be most cost-effective due to cost synergies between the latter two options. Furthermore, such a pathway has the largest GHG reduction potential of $154 \%$ compared to the 2012 base case, resulting in negative emissions. This pathway can be realized with on average negative costs of $-25 € / \mathrm{tCO}_{2}$-eq when $75 \%$ of the emissions are reduced due to the revenues from efficiency measures, while this would be $-5 €$ / $\mathrm{tCO}_{2}$-eq in a CCS pathway based on oxyfuel combustion. In a sensitivity analysis, it was found that costs are highly dependent on uncertainties in especially energy prices, but also techno-economic parameters. When CCS is fully deployed, marginal avoidance costs vary between 44 and $115 € /$ $\mathrm{tCO}_{2}$-eq, while full deployment of biomass gasification with CCS results in a range of -64 to $98 € / \mathrm{tCO}_{2}$-eq.

The method has proven useful to evaluate emissions reduction strategies in an industrial plant based on criteria such as GHG avoidance cost and GHG reduction potential. It provides insight in the potential of various mitigation options, their uncertainty and the main parameters affecting their performance, which is also useful information for plant owners when doing detailed follow-up analyses and determining risks related to potential investments in these technologies. The method can also be applied to other refineries and industries to identify deployment pathways, but requires detailed techno-economic data on core processes as well as the inclusion of other mitigation options, such as electrification of processes, use of secondary materials and geothermal energy. Furthermore, the method could be extended to ensure that complete optimization of emissions reduction pathways is achieved. Given the overlap in cost ranges, evaluation of pathways should consider decommissioning of existing capital stock and the deployment of biomass supply chains and CCS infrastructure. Furthermore, temporal dynamics of the energy systems in which the industrial plant is embedded, such as changes in energy prices and the availability of cheap hydrogen, should be integrated in the analysis in a more sophisticated manner. Lastly, potential barriers to low-carbon technology investment should be considered, especially those related to CCS and biomass gasification which have struggled to attract serious levels of commitment and investment to date.

\section{Acknowledgement}

This research has been carried out in the context of the CATO- 2program. CATO-2 is the Dutch national research program on $\mathrm{CO}_{2}$ Capture and Storage technology (CCS). The program is financially supported by the Dutch government (Ministry of Economic Affairs) and the CATO-2 consortium parties. The authors gratefully acknowledge the aid and valuable discussions with Prof. Dr. Ernst Worrell (Utrecht University). 


\section{Appendix A}

Future trends were analyzed to make projections for the baseline GHG emissions for the year 2020 and 2030, which reflect the short and medium term, respectively. Johansson et al. [14] and Rootzén and Johnsson [58] analyzed scenarios on future market trends and trends for fuel quality in the EU refinery sector by reviewing studies from government and industry organizations [31,59], and by collecting data from the EU statistical database. This approach was adopted for the present study and updated using additional studies [29,30]. Furthermore, the approach was extended to the global level based on the World Energy Outlook (WEO) 2013 [27], Energy Technology Perspective [60], and Global Energy Assessment [28]. The following trends have been observed:

- The global refining sector will be re-shaped in the coming decades owing to a declining oil demand in the OECD countries alongside an increasing demand in non-OECD areas like Asia and the Middle East. Following liquid fuel demand, future refinery capacity additions are expected in nonOECD countries. The future global refinery capacity additions, however, will depend strongly on the crude oil demand increase, which ranges from 0.0 to $1.0 \mathrm{Gt} / \mathrm{y}$ ( -3 to $42 \mathrm{EJ} / \mathrm{y}$ ) ${ }^{14}$ for the year 2030 compared to 2012 in the different scenarios of the WEO. For 2012 , an excess global crude oil refinery capacity was calculated of around $0.2 \mathrm{Gt} / \mathrm{y}(11 \mathrm{EJ} / \mathrm{y})$. At the same time, new refinery projects with a total crude oil capacity of over $0.5 \mathrm{Gt} / \mathrm{y}(22 \mathrm{EJ} / \mathrm{y})$ have been announced by several countries [27]. This overhang will lead to more competition for internationally traded crude and result in capacity cuts, especially in the United States and the EU where crude oil demand is expected to decline and refineries are older and less sophisticated than in other parts of the world. Strains on the oil refining industry will be amplified by a growing share of fuels (biofuels and oil supply coming from natural gas and coal) bypassing the refining system. Another notable trend is the global shift in demand from heavy (i.e. fuel oils and marine fuels) and light distillates (i.e. gasoline and naphtha) to middle distillates (i.e. diesel and jet fuel). In the EU, a constant increase in the middle distillates/gasoline $(\mathrm{MD} / \mathrm{G})$ ratio can be observed as a result of transport and fiscal policies that favor diesel use over gasoline. If there will be no reversal in policies, significant investments are required in new processing capacity - mainly hydrocracking, coking and desulphurization - to accommodate these throughput trends. The EU demand for fossil-based refined products is expected to decline over the coming decades from $709 \mathrm{Mt} / \mathrm{y}(30 \mathrm{EJ} / \mathrm{y})$ in 2008 to $603 \mathrm{Mt} / \mathrm{y}(26 \mathrm{EJ} / \mathrm{y})$ in 2030, caused in large part by legislative mandates to improve vehicle efficiency and increase the share of alternative fuels (e.g. biofuels, electricity, hydrogen) [29]. Despite the fall in total energy use in the EU refinery sector, the specific refinery energy consumption and $\mathrm{CO}_{2}$ emissions are expected to rise due to higher demand for MD products. ${ }^{15}$ The overall EU refining capacity is projected to drop with $0.4 \mathrm{Mt} / \mathrm{d}(6 \mathrm{EJ} / \mathrm{y})$ up till 2035 owing to the combination of declining North Sea crude oil output, increased global competition, and loss of gasoline export markets [27].

- Legislation on fuel quality (mainly sulphur and aromatic levels) has been tightened over the last decades in several parts of the world, including the EU, and will become more stringent in the future. In the EU, more stringent standards will follow for marine fuels in the coming decade. Stricter quality specifications require significant investments in additional fuel purification capacity, resulting in higher specific energy requirement (SER) and concomitant $\mathrm{CO}_{2}$ emissions.

Both trends are expected to partly affect the $\mathrm{CO}_{2}$ emission profile of the case refinery. As indicated by Johansson et al. [14], complex refineries can rather easily diversify and change the product output mix, which enables them to cope with changes in fuel demand, and are thus more likely to survive in a competitive environment than simple hydroskimming refineries with low conversion capacity that need to make large investments in new processing capacity. Although the overall EU demand for refined product declines, it was assumed that the current product output level of the case refinery will be maintained. Nevertheless, the SER and $\mathrm{CO}_{2}$ emissions in the refinery were assumed to increase as a result of the increasing $\mathrm{MD} /$ $\mathrm{G}$ ratio. Quantitative projections of future $\mathrm{CO}_{2}$ emissions in the EU refining industry as a result of changes in the $\mathrm{MD} / \mathrm{G}$ ratio and fuel quality requirements were made based on the refining model of the CONCAWE association [29,31]. Based on a projected increase in the MD/G ratio from 2.4 in 2012 to 2.8 in 2020 and 3.3 in 2030 in the CONCAWE base case scenario, the specific refinery $\mathrm{CO}_{2}$ emissions ( $\mathrm{tCO}_{2} / \mathrm{t}$ product) were found to increase with $8 \%$ in 2020 and $17 \%$ in 2030 compared to 2012. Assuming the relative change in total $\mathrm{CO}_{2}$ emissions for the EU refining sector applies to the individual refinery as well, this corresponds with additional $\mathrm{CO}_{2}$ emissions of $0.3 \mathrm{MtCO}_{2} / \mathrm{y}$ in 2020 , increasing to $0.6 \mathrm{MtCO} / \mathrm{y}$ in 2030 . ${ }^{16}$ Furthermore, as a result of planned stricter quality regulations, the case refinery's $\mathrm{CO}_{2}$ emissions were found to increase with $11 \%$ up till 2020 ( 0.5 $\mathrm{MtCO}_{2} / \mathrm{y}$ ) compared to 2012. The planned tightening in regulations applies particularly to marine fuels. Additional legal changes applying to other refinery products (e.g. gasoline, jet fuel, diesel, heating oil and heavy fuel oil) might be introduced in the period 2020-2030. These potential product quality changes could result in an increase of $16 \%\left(0.6 \mathrm{MtCO}_{2} / \mathrm{y}\right)$ in the refinery's $\mathrm{CO}_{2}$ emissions compared to 2012.

\section{Appendix B}

\section{B.1 Energy efficiency measures}

The largest primary energy reductions in the short term can be achieved via heat integration between the distillation units $(\sim 3 \%)$ and improvements in energy management \& control, such as the implementation of organization-wide energy management programs, energy monitoring and control systems $(\sim 3 \%)$. Other short term EEMs are: the replacement, adjustment and upgrading of pumps and electric motor systems; improved insulation of steam distribution systems and steam traps; fouling mitigation (e.g. online cleaning of heat exchangers); and improved furnace performance. The latter can be achieved, for instance, via improved maintenance, inflow air preheating and/or the use of low-NOx burners, which reduces the need for energy consumption in the downstream selective catalytic reduction (SCR) unit. The last two short term EEMs are efficiency improvements in hydrogen production \& management as well as more efficient flaring systems, such as flare gas recovery systems and/or the use of

\footnotetext{
${ }^{14}$ The original values in the underlying sources were given in million barrels per day or EJ/y. For crude oil, an energy content of $6.12 \mathrm{GJ} / \mathrm{bbl}$ and a density of $0.14 \mathrm{t} / \mathrm{bbl}$ crude oil were assumed to compute the values presented in this study.

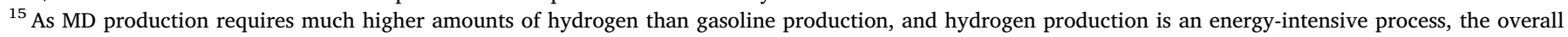
balance tends towards increased energy use and $\mathrm{CO}_{2}$ emissions at high $\mathrm{MD} / \mathrm{G}$ ratios.

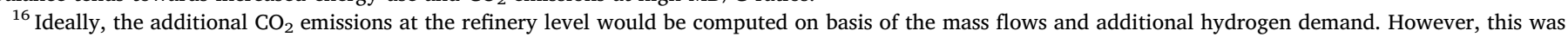
impossible due to limited data availability on the core refinery processes. The $\mathrm{CO}_{2}$ projections are therefore indicative in nature.
} 
electronic ignition system. The joint primary energy reduction of short term EEMs amounts up to 15-16\% (see Table B1).

For the medium term, large primary energy reductions are expected to come from advanced desulphurization systems, such as advanced hydrotreating or oxidative desulphurization $(\sim 10 \%)$. Energy savings can also be realized through advanced separation systems; for example, dividing wall columns, which combine two conventional distillation columns into one, show lower heat losses due to better heat transfer. Lastly, a newly built gas turbine can be pre-coupled to the in situ SR so as to utilize the hot exhaust gas of the gas turbine to supply heat to the SR furnace. In total, an estimated reduction in primary energy use of $19-20 \%$ was computed for the medium term (see Table B1). A more detailed description of the EEMs can be found in Worrell et al. [34].

The EEMs improved energy management \& control and heat integration \& waste heat recovery apply to the overall refinery site and show interaction with each other and with the other 'isolated' EEMs: steam distribution system, fouling mitigation, and improved furnace performance. Assuming that heat integration \& waste heat recovery will be implemented after the 'isolated' EEMs, and followed by energy management \& control, the primary energy reductions of these two refinery wide EEMs are reduced from $2.0 \%$ to $1.9 \%$ and $3.0 \%$ to $2.8 \%$, respectively.

\section{Table B1}

Input data for energy saving measures identified for the refinery for the short and medium term. The data are based on Worrell et al. [34]; the lifetimes are based on an expert's estimations [98]. The reductions are related to the total heat, electricity, and primary energy use in the refinery in the year 2012, thus excluding growth in emissions due to future trends.

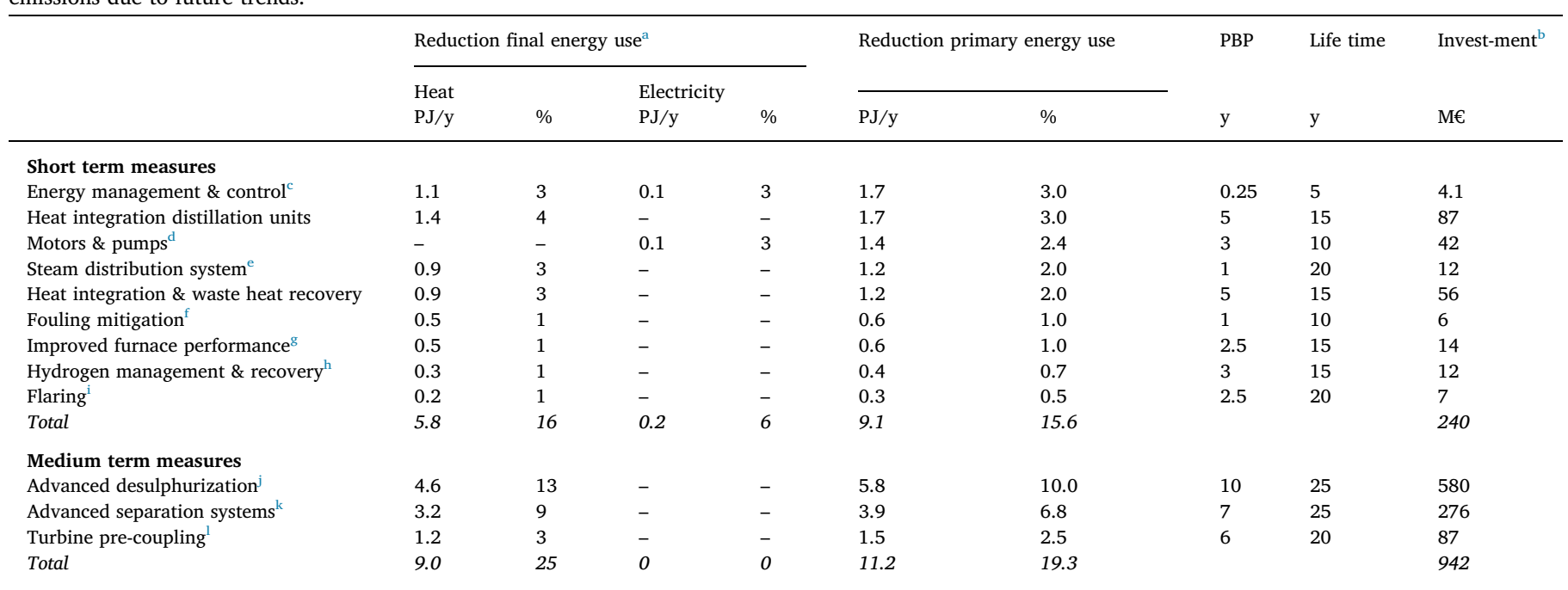

a A furnace efficiency of $80 \%$ and a single-cycle gas turbine CHP with an electric efficiency of $27 \%$ and heat efficiency of $56 \%$ were assumed to compute the heat and electricity savings, respectively. The primary energy reduction is assumed to result in natural gas savings. In case refinery fuels are saved, it was assumed that these can be used elsewhere in the refinery where they replace natural gas, or in case where this is not possible, to be sold to other parties against the same economic value per energy unit and carbon footprint as natural gas.

$\mathrm{b}$ The investment costs were calculated using the simple payback period equation as presented in Section 2.2. The annual costs C (M€/y) were assumed to be zero.

${ }^{c}$ E.g. the implementation of organization-wide energy management programs, energy teams or energy monitoring and control systems.

$\mathrm{d}$ The replacement, adjustment and upgrading of pumps and electric motor systems.

e E.g. improved insulation and steam trap improvement.

${ }^{\mathrm{f}}$ E.g. online cleaning of heat exchangers.

${ }^{g}$ E.g. better furnace maintenance, inflow air preheating and/or the use of low- $\mathrm{NO}_{\mathrm{x}}$ burners. The latter reduces the need for energy consumption in the selective catalytic reduction unit.

${ }^{h}$ E.g. hydrogen network integration to match different hydrogen sources with uses based on the quality of the hydrogen streams.

${ }^{i}$ E.g. implementing flare gas recovery systems and/or the use of electronic ignition system, which only burns fuel gas when needed, instead of flare systems with a continuously burning pilot flame.

${ }^{j}$ E.g. advanced hydrotreating or oxidative desulphurization.

${ }^{k}$ E.g. a dividing wall-column, which combines two conventional distillation columns into one resulting in a better heat transfer and lower capital cost.

${ }^{1}$ E.g. a newly built gas turbine can be pre-coupled to the in situ SR so as to utilize the hot exhaust gas of the gas turbine to supply heat to the SR furnace.

\section{B.2 $\mathrm{CO}_{2}$ capture and storage}

Three first generation $\mathrm{CO}_{2}$ capture technologies are assessed: post-, pre- and oxyfuel combustion capture. While post-combustion capture has already been demonstrated on a commercial scale, pre- and oxyfuel combustion are not expected to be deployed in t. The studied concepts are:

- Post-combustion capture, in which $\mathrm{CO}_{2}$ is separated from a flue gas stream. In this study, the $\mathrm{CO}_{2}$ is extracted using the chemical solvent monoethanolamine (MEA). ${ }^{17}$ Post-combustion is an add-on technology as no drastic changes have to be made to the process units [8].

- Oxyfuel combustion, in which fuel is burned with nearly pure oxygen (instead of air), thereby creating an almost pure $\mathrm{CO}_{2}$ off-gas. The oxygen is produced in a cryogenic Air Separation Unit (ASU). As several adjustments and additional equipment (e.g. piping, ducting, flue gas recirculation

\footnotetext{
${ }^{17}$ Although improved solvents with lower specific energy requirements (SER) than MEA are available today, no reliable data was found on these solvents' SER for flue gases with different volumetric $\mathrm{CO}_{2}$ concentrations.
} 
fan) are needed to convert boilers, furnaces and gas turbines to oxyfuel mode, oxyfuel combustion is considered to be a retrofit technology [8]. - Pre-combustion capture, in which the fuel is decarbonized prior to the combustion step. In this study, methane and refinery gas are converted to hydrogen in a newly built SR. The $\mathrm{CO}_{2}$ is captured from the high-pressure (HP) process gas between the watergas shift (WGS) reactor and Pressure Swing Adsorption (PSA) unit using the mixed solvent ADIP-X (methyldiethanolamine mixed with piperazine). Pre-combustion is also considered to be a retrofit technology as several adjustments need to be made to refinery infrastructure [35].

The key data of the $\mathrm{CO}_{2}$ capture technologies can be found in Tables $\mathrm{B} 2-\mathrm{B} 4$. The $\mathrm{CO}_{2}$ transport and storage costs $(16 € / \mathrm{tCO} 2)$ were taken from the Zero Emissions Platform $[61,62]$. Electricity and steam required for the post- and pre-combustion routes are produced in a newly built NGCC-CHP unit from which the $\mathrm{CO}_{2}$ is also captured. Electricity demand for the oxyfuel route is purchased from the grid as electricity production in a newlybuilt gas turbine was found to be more expensive. As the newly built CHP units are dimensioned towards the heat demand, often excess electricity is produced, which is sold to the grid. Additional equations, assumptions and data used to calculate the techno-economic performance of the CHP units and CCS configurations can be found in Berghout et al. [38,45,63].

Table B2

Techno-economic parameters for post-combustion capture. The economic data pertain to a post-combustion system capturing annually $1.0 \mathrm{MtCO}_{2}$ from flue gas streams of both 4 and $12-14 \mathrm{vol} \% \mathrm{CO}_{2}$ using one absorber and one stripper. Based on: $[56,89,96] .^{\mathrm{a}}$

\begin{tabular}{|c|c|c|c|}
\hline & Unit & Value & References \\
\hline \multicolumn{4}{|l|}{ Technical } \\
\hline $\mathrm{CO}_{2}$ capture ratio & $\%$ & 87 & [89] \\
\hline \multicolumn{4}{|c|}{ Maximum processing capacity per unit } \\
\hline Absorber & $\mathrm{ktCO}_{2} / \mathrm{d}$ & 3 & {$[102,103]$} \\
\hline Stripper & $\mathrm{ktCO}_{2} / \mathrm{d}$ & 10 & {$[102,103]$} \\
\hline $\mathrm{CO}_{2}$ compressor & $\mathrm{ktCO}_{2} / \mathrm{d}$ & 8 & [104] \\
\hline Electricity flue gas blower & $\mathrm{GJ}_{\mathrm{e}} / \mathrm{tCO}_{2}$ & 0.35 & [92] \\
\hline Regeneration heat ${ }^{\mathrm{b}}$ & $\mathrm{GJ}_{\mathrm{th}} / \mathrm{tCO}_{2}$ & $3.5-4.0$ & [95] \\
\hline $\mathrm{CO}_{2}$ capture (pumps and fans) ${ }^{\mathrm{b}}$ & $\mathrm{GJ}_{\mathrm{e}} / \mathrm{tCO}_{2}$ & $0.1-0.3$ & {$[90,91]$} \\
\hline $\mathrm{CO}_{2}$ treatment \& compression & $\mathrm{GJ}_{\mathrm{e}} / \mathrm{tCO}_{2}$ & 0.6 & [89] \\
\hline \multicolumn{4}{|l|}{ CAPEX } \\
\hline Flue gas ducting & $\mathrm{M} € / \mathrm{MtCO}_{2} / \mathrm{y}$ & $12^{\mathrm{c}}$ & [92] \\
\hline Modifications to stacks & $\mathrm{M} € /$ stack & 0.1 & [92] \\
\hline $\mathrm{CO}_{2}$ capture equipment ${ }^{\mathrm{d}}$ & $\mathrm{M} € / \mathrm{MtCO}_{2} / \mathrm{y}$ & $\begin{array}{l}75 \text { (4 vol\%); } 49 \\
(12-14 \text { vol\%) }\end{array}$ & {$[56,89,96]$} \\
\hline $\mathrm{CO}_{2}$ treatment \& compression ${ }^{\mathrm{d}}$ & $\mathrm{M} € / \mathrm{MtCO}_{2} / \mathrm{y}$ & 14 & {$[56,89,96]$} \\
\hline \multicolumn{4}{|l|}{ Economic scaling factor } \\
\hline Amine absorber & & 0.67 & {$[105,106]$} \\
\hline Stripper & & 0.67 & {$[25,106]$} \\
\hline Compressor & & 0.67 & {$[104,105]$} \\
\hline \multicolumn{4}{|l|}{ OPEX } \\
\hline Labor & $€ / \mathrm{tCO}_{2}$ & $0.2^{\mathrm{e}}$ & {$[56,89,96]$} \\
\hline Administration \& overhead & $\begin{array}{l}\% \text { of labor } \\
\text { cost }\end{array}$ & 28 & [96] \\
\hline Taxes \& Insurances & $€ / \mathrm{tCO}_{2}$ & 2.0 & [96] \\
\hline Maintenance & $\%$ of TPC & 3.8 & [96] \\
\hline Water usage & $€ / \mathrm{tCO}_{2}$ & 1.4 & [96] \\
\hline MEA & $€ / \mathrm{tCO}_{2}$ & 0.5 & [96] \\
\hline Activated carbon & $€ / \mathrm{tCO}_{2}$ & 0.1 & [96] \\
\hline Ammonia & $€ / \mathrm{tCO}_{2}$ & 0.2 & [96] \\
\hline Corrosion inhibitor & $€ / \mathrm{tCO}_{2}$ & 0.0 & [96] \\
\hline SCR catalyst ${ }^{f}$ & $€ / \mathrm{tCO}_{2}$ & 0.1 & [96] \\
\hline Other chemicals & $€ / \mathrm{tCO}_{2}$ & 0.2 & [96] \\
\hline
\end{tabular}

${ }^{a}$ The parameters used for economic costs are based on three detailed studies $[56,89,96]$, which describe post-combustion capture at a pulverized coal-fired (PC) power plant (12-14 vol\% $\mathrm{CO}_{2}$ concentration) and at a natural gas fired combined cycle (NGCC, 3-4 vol $\% \mathrm{CO}_{2}$ concentration). Since the $\mathrm{CO}_{2}$ concentration in the flue gases can change significantly among and within industrial plants, data from both the capture systems applied at the PC and NGCC power plants were used to account for this factor.

b Regeneration heat and electricity needed for flue gas with volumetric $\mathrm{CO}_{2}$ concentrations in the range of 4-16\%; the specific regeneration energy $\left(\mathrm{GJ}\right.$ th $\left./ \mathrm{tCO}_{2} ; \mathrm{GJ}_{\mathrm{e}} / \mathrm{tCO}_{2}\right)$ decreases with higher volumetric $\mathrm{CO}_{2}$ concentrations. It is assumed there is no effect of scale on the specific energy consumption, which is concluded from a literature review [107].

c A total flue gas ducting system of $5 \mathrm{~km}$ was assumed for the refinery.

d All capital costs were standardized to and corrected for the amount of $\mathrm{CO}_{2}$ captured of $1.0 \mathrm{MtCO}_{2}$ per year using one absorber and stripper. Scaling factors were used to account for differences in $\mathrm{CO}_{2}$ capture capacity. The cost category $\mathrm{CO}_{2}$ capture equipment represents the direct contact cooler (DCC), absorber and stripper; the cost category $\mathrm{CO}_{2}$ treatment \& compression comprises a $\mathrm{CO}_{2}$ drying, purification, cooling (DPC) and compression unit.

e The average amount of labor hours were taken from CESAR [89], IEA GHG [56] and NETL [96], and multiplied with a European wage for an operator of $60,000 € / \mathrm{FTE} / \mathrm{y}$ [56].

${ }^{\mathrm{f}} \mathrm{SCR}$ stands for selective catalytic reduction. 
Table B3

Techno-economic parameters for oxyfuel combustion capture.

\begin{tabular}{|c|c|c|c|}
\hline & Unit & Value & Reference \\
\hline \multicolumn{4}{|l|}{ Technical } \\
\hline $\mathrm{CO}_{2}$ capture ratio & $\%$ & 87 & {$[108,109]$} \\
\hline \multicolumn{4}{|l|}{ Maximum processing capacity } \\
\hline Air Separation Unit & $\mathrm{ktO}_{2} / \mathrm{d}$ & 6 & [110] \\
\hline Oxygen production & $\mathrm{GJ}_{\mathrm{e}} / \mathrm{tO}_{2}$ & $0.7^{\mathrm{a}}$ & [94] \\
\hline \multicolumn{4}{|l|}{ Stoichiometric $\mathrm{O}_{2}: \mathrm{CO}_{2}$ combustion ratio (weight basis) ${ }^{\mathrm{b}}$} \\
\hline Cokes (catalytic cracker) & & 0.73 & \\
\hline Natural gas & & 1.43 & \\
\hline Refinery gas furnaces & & 1.45 & {$[78,108]$} \\
\hline Excess oxygen use & $\%$ & 3 & [111] \\
\hline Fuel savings furnaces ${ }^{\mathrm{b}}$ & $\%$ & 8.3 & {$[108,109]$} \\
\hline $\mathrm{CO}_{2}$ treatment \& compression ${ }^{\mathrm{C}}$ & $\mathrm{GJ}_{\mathrm{e}} / \mathrm{tCO}_{2}$ & 0.5 & [93] \\
\hline \multicolumn{4}{|l|}{ CAPEX } \\
\hline Furnace modification & $\mathrm{M} € / \mathrm{MtCO}_{2} / \mathrm{y}$ & $1^{\mathrm{d}}$ & {$[108,109]$} \\
\hline Air Separation Unit (ASU) & $\mathrm{M} € / \mathrm{ktO}_{2} / \mathrm{y}$ & $53^{\mathrm{e}}$ & {$[42,108,109,112,113]$} \\
\hline Cooling water system & $\mathrm{M} € / \mathrm{MtCO}_{2} / \mathrm{y}$ & 12 & {$[108,109]$} \\
\hline Flue gas gathering system & $\mathrm{M} € / \mathrm{MtCO}_{2} / \mathrm{y}$ & 7 & {$[108,109]$} \\
\hline $\mathrm{CO}_{2}$ treatment \& compression & $\mathrm{M} € / \mathrm{MtCO}_{2} / \mathrm{y}$ & 23 & [113] \\
\hline Economic scaling factor ASU & & 0.63 & {$[41,105,113]$} \\
\hline \multicolumn{4}{|l|}{ OPEX } \\
\hline Labor & $€ / \mathrm{tCO}_{2}$ & $1.0^{\mathrm{f}}$ & {$[108,109]$} \\
\hline Administration \& overhead & $€ / \mathrm{tCO}_{2}$ & 0.1 & {$[108,109]$} \\
\hline Maintenance & $€ / \mathrm{tCO}_{2}$ & 3.0 & {$[108,109]$} \\
\hline Taxes \& Insurances & $€ / \mathrm{tCO}_{2}$ & 3.0 & {$[108,109]$} \\
\hline Water & $€ / \mathrm{tCO}_{2}$ & 1.6 & {$[108,109]$} \\
\hline Consumables & $€ / \mathrm{tCO}_{2}$ & 0.3 & {$[108,109]$} \\
\hline
\end{tabular}

a The current SER for cryogenic oxygen production was found to be in the range of $0.6-0.8 \mathrm{GJ}_{\mathrm{e}} / \mathrm{tO}_{2}\left(160-220 \mathrm{kWh}_{\mathrm{e}} / \mathrm{tO}_{2}\right)$ [114].

b Assumptions were made on the stoichiometric $\mathrm{O}_{2}: \mathrm{CO}_{2}$ combustion ratio due to insufficient information on the fuel composition in the refinery. In the catalytic cracker, oxygen is used to burn the coke that is deposited on the surface of the catalyst $\left(\mathrm{C}+\mathrm{O}_{2} \rightarrow \mathrm{CO}_{2}\right)$, resulting in a molar ratio of $1: 1$, which translates to a mass ratio of $0.73(32 / 44)$. The mass ratio for the combustion of natural gas in the in situ gas turbine/CHP units (1.43) was derived from the volumetric $\mathrm{O}_{2}: \mathrm{CO}_{2}$ ratio as presented by $\mathrm{C}+\mathrm{B}$ [115]. The oxygen requirement for the refinery gases was based on two studies performing detailed analyses into oxyfuel combustion of refinery fuel gases. The mass ratio derived from these studies was 1.44 [108] and 1.49 [78]. A value of 1.45 was used in this study. The high stoichiometric $\mathrm{O}_{2}: \mathrm{CO}_{2}$ mass ratio for refinery fuel gas is mainly due to the high methane and hydrogen concentrations in the fuel streams. However, as fuel gas compositions tend to vary considerably (also within refineries), the impact of the oxygen demand was indirectly examined by varying the energy use for oxygen production in the sensitivity analysis.

${ }^{c}$ The treatment unit cools, purifies and dries the hot, wet $\mathrm{CO}_{2}$ coming from the process units.

d Average values calculated from the total furnace modification costs in Allam et al. [108,109]. It was assumed there is no scaling effect for furnace modifications considering the small scale of most furnaces.

e Average value based on Allam et al. [108,109], Meerman et al. [42], Spero [112] and IEA GHG [113] and valid for a cryogenic ASU and the oxygen compressor to 40 bar.

${ }_{\mathrm{f}}$ No data were available on the amount of operating manpower hours in Allam et al. [108,109]; only monetary values were presented.

Table B4

Techno-economic parameters for pre-combustion capture.

\begin{tabular}{|c|c|c|c|}
\hline & Unit & Value & References \\
\hline \multicolumn{4}{|l|}{ Technical } \\
\hline Feed natural gas needed for $\mathrm{H}_{2}$ production & $\mathrm{GJ}_{\mathrm{p}} / \mathrm{tH}_{2}$ & 122 & [88] \\
\hline Fuel natural gas needed for $\mathrm{H}_{2}$ production & $\mathrm{GJ}_{\mathrm{p}} / \mathrm{tH}_{2}$ & 43 & [88] \\
\hline Electricity needed for $\mathrm{H}_{2}$ production & $\mathrm{GJ}_{\mathrm{e}} / \mathrm{tH}_{2}$ & 2.2 & [88] \\
\hline \multicolumn{4}{|l|}{$\mathrm{CO}_{2}$ produced } \\
\hline Production process $\left(\mathrm{CO}_{2}\right.$ in process gas) & $\mathrm{tCO}_{2} / \mathrm{tH}_{2}$ & 6.9 & [88] \\
\hline SR furnace $\left(\mathrm{CO}_{2}\right.$ in flue gas $)$ & $\mathrm{tCO}_{2} / \mathrm{tH}_{2}$ & 3.2 & [88] \\
\hline HP steam from waste heat of the $\mathrm{SR}^{\mathrm{a}}$ & $\mathrm{GJ}_{\mathrm{th}} / \mathrm{tH}_{2}$ & 25 & [116] \\
\hline $\mathrm{CO}_{2}$ capture ratio process gas & $\%$ & 95 & [37] \\
\hline \multicolumn{4}{|l|}{ Maximum processing capacity } \\
\hline Steam reformer & $\mathrm{ktH}_{2} / \mathrm{d}$ & 10 & [117] \\
\hline Heat for regeneration ADIP-X & $\mathrm{GJ}_{\mathrm{th}} / \mathrm{tCO}_{2}$ & 1.97 & [37] \\
\hline Power for regeneration ADIP-X & $\mathrm{GJ}_{\mathrm{e}} / \mathrm{tCO}_{2}$ & 0.04 & [37] \\
\hline Power for $\mathrm{CO}_{2}$ treatment and compression & $\mathrm{GJ}_{\mathrm{e}} / \mathrm{tCO}_{2}$ & 0.3 & [37] \\
\hline \multicolumn{4}{|l|}{ CAPEX } \\
\hline SR plant (incl. WGS, PSA, SCR) & $\mathrm{M} € / \mathrm{MtCO}_{2} / \mathrm{y}$ & 87 & {$[88,118-120]$} \\
\hline $\mathrm{CO}_{2}$ capture equipment & $\mathrm{M} € / \mathrm{MtCO}_{2} / \mathrm{y}$ & 19 & {$[88,117-120]$} \\
\hline DPC \& Compression & $\mathrm{M} € / \mathrm{MtCO}_{2} / \mathrm{y}$ & 24 & {$[88]$} \\
\hline Modified burners & $\mathrm{M} € / \mathrm{MtCO}_{2} / \mathrm{y}$ & 0.1 & [78] \\
\hline Economic scaling factor SR plant & & 0.67 & [105] \\
\hline \multicolumn{4}{|l|}{ OPEX } \\
\hline \multirow[t]{2}{*}{ Labor } & $€ / \mathrm{tCO}_{2}$ & $0.4^{\mathrm{b}}$ & [88] \\
\hline & & & ed on next pag \\
\hline
\end{tabular}


Table B4 (continued)

\begin{tabular}{|c|c|c|c|}
\hline & Unit & Value & References \\
\hline Administration \& overhead & $\%$ of labor costs & 20 & [88] \\
\hline Taxes \& Insurances & $€ / \mathrm{tCO}_{2}$ & 3.7 & [88] \\
\hline Maintenance & $€ / \mathrm{tH}_{2}$ & 4.5 & [88] \\
\hline Demineralized water & $€ / \mathrm{tCO}_{2}$ & 0.9 & [88] \\
\hline Chemicals $^{c}$ & $€ / \mathrm{tCO}_{2}$ & 2.0 & [88] \\
\hline
\end{tabular}

\footnotetext{
a The SR generates a lot of high-pressure steam $\left(75\right.$ bar, $\left.350^{\circ} \mathrm{C}\right)$ in a waste heat recovery boiler. In theory, $30 \mathrm{GJ}$ th $/ \mathrm{tH}_{2}$ of $\mathrm{WH}$ would become available. Considering heat losses, it is assumed that $25 \mathrm{GJ}_{\mathrm{th}} / \mathrm{tH}_{2}$ of steam can be produced.

b The average amount of labor hours were taken from CESAR [89], IEA GHG [56] and NETL [96], and multiplied with a European wage for an operator of 60,000€/FTE/y [56].

c SR and WGS catalysts, PSA sorbent, HP process gas solvent, MEA, SCR catalyst.
}

\section{B.3 Biomass gasification}

The first biomass route is the production and processing of syngas through biomass gasification (BIG), which is subsequently converted into electricity, chemicals and/or transportation fuels. The BIG route has been investigated in numerous studies over the years, e.g. [43,52]. Gasification is a thermo-chemical process that converts carbonaceous materials (i.c. biomass) into syngas (mixture of mainly $\mathrm{CO}$ and $\mathrm{H}_{2}$ ) carried out at high temperatures $\left(>900^{\circ} \mathrm{C}\right.$ ) and by using a sub-stoichiometric amount of oxygen [64]. Next, a purification and optimization step is needed before the syngas can be converted into the final products. Four sub-routes are investigated for the case study, which are all preceded by a sour water-gas shift reactor and acid gas removal (AGR) process: (1) the production of steam and electricity by combusting the syngas/ $\mathrm{H}_{2}$ and combustible waste streams (diluted with $\mathrm{N}_{2}$ ) in the CHP units (BIG-CHP); (2) the production of hydrogen by shifting the syngas in a sweet water-gas shift reactor and extracting the hydrogen from the resulting product gas using a pressure swing adsorption (PSA) unit $\left(\mathrm{BIG}-\mathrm{H}_{2}\right)$; (3) the production of Fischer-Tropsch (FT) fuels by converting the syngas to linear alkanes and 1-alkenes, followed by a hydrocracking process to upgrade the intermediate products to FT-syncrude, and subsequently by a distillation process to separate the FT-fuels into FT-gasoline and FT-diesel (BIG-FT); and (4) all three output products combined (BIG-combi). The acid compounds are converted to liquid sulphur in the Claus/SCOT unit. All four sub-routes can be combined with CCS. $\mathrm{CO}_{2}$ capture after the acid gas removal step is particularly interesting for two reasons. First, the process already requires the removal of $\mathrm{CO}_{2}$ from the process gas. Second, the high partial pressure of $\mathrm{CO}_{2}$ makes capture using a physical solvent relatively cheap.

Table B5 shows there is excess electricity production in the BIG-FT sub-route, excess steam production in the BIG- $\mathrm{H}_{2}$ sub-route and a shortage of electricity production in the BIG-CHP, BIG- $\mathrm{H}_{2}$ and BIG-combi sub-routes. These deviating electricity and steam flows are due to an assumed fixed heat-power ratio for the CHP units (see footnote c in Table B5), and excess heat and waste gas streams, which were assumed to be utilized for additional steam and electricity production, respectively. Excess steam and electricity were assumed to be sold to third parties and the grid, respectively, whereas an electricity shortage was compensated by purchasing electricity from the grid.

Table B5

Input data for biomass gasification sub-routes. Based on NEA [26,67] and Meerman et al. [42,43].

\begin{tabular}{|c|c|c|c|c|c|c|c|c|c|c|}
\hline & \multirow[t]{2}{*}{ Unit } & \multirow[t]{2}{*}{ REF } & \multicolumn{2}{|c|}{ BIG-CHP } & \multicolumn{2}{|c|}{ BIG-H ${ }_{2}$} & \multicolumn{2}{|l|}{ BIG-FT } & \multicolumn{2}{|c|}{ BIG-combi } \\
\hline & & & Vent & CCS & Vent & CCS & Vent & CCS & Vent & CCS \\
\hline \multicolumn{11}{|l|}{ Input refinery } \\
\hline Natural gas ${ }^{a}$ & $\mathrm{MW}_{\mathrm{LHV}}$ & 1167 & 607 & 607 & 560 & 560 & 1167 & 1167 & 0 & 0 \\
\hline \multirow[t]{3}{*}{ TOPS } & $\mathrm{MW}_{\mathrm{LHV}}\left(\mathrm{MW}_{\mathrm{HHV}}\right)$ & - & 473 & 511 & 401 & 401 & $\begin{array}{l}937 \\
(1000)\end{array}$ & $\begin{array}{l}937 \\
(1000)\end{array}$ & 1499 & 1499 \\
\hline & $\mathrm{t}_{\mathrm{dry}} / \mathrm{h}$ & - & 84 & 91 & 71 & 71 & 167 & 167 & 267 & 267 \\
\hline & $\mathrm{tC} / \mathrm{h}$ & - & 166 & 179 & 141 & 141 & 329 & 329 & 527 & 527 \\
\hline \multicolumn{11}{|c|}{ Output refinery ${ }^{\mathrm{b}}$} \\
\hline Steam ${ }^{\mathrm{c}, \mathrm{e}}$ & $\mathrm{MW}_{\text {th }}$ & 314 & 314 & 314 & $406^{\mathrm{d}}$ & $406^{\mathrm{d}}$ & 314 & 314 & 314 & 314 \\
\hline Elec. $\mathrm{CHP}^{\mathrm{c}, \mathrm{e}}$ & $\mathrm{MW}_{\mathrm{e}}$ & 182 & 72 & 51 & $156^{\mathrm{f}}$ & $149^{\mathrm{f}}$ & $308^{\mathrm{h}}$ & $286^{\mathrm{h}}$ & 86 & 86 \\
\hline Hydrogen ${ }^{e, g}$ & $\mathrm{MW}_{\mathrm{H} 2}$ & 255 & 255 & 255 & 255 & 255 & 255 & 255 & 255 & 255 \\
\hline FT-fuels & $\mathrm{MW}_{\mathrm{FT}}$ & - & - & - & - & - & 458 & 458 & 458 & 458 \\
\hline \multicolumn{11}{|l|}{$\Delta$ output REF } \\
\hline Steam & $\mathrm{MW}_{\text {th }}$ & 0 & 0 & 0 & 92 & 92 & 0 & 0 & 0 & 0 \\
\hline Electricity & $\mathrm{MW}_{\mathrm{e}}$ & 0 & -110 & -131 & -26 & -33 & 126 & 104 & -61 & -96 \\
\hline \multicolumn{11}{|l|}{ GHG emissions } \\
\hline Emitted & $\mathrm{tCO}_{2}-\mathrm{eq} / \mathrm{h}$ & 512 & 385 & 229 & 425 & 287 & 390 & 193 & 201 & -116 \\
\hline Captured & $\mathrm{tCO}_{2} / \mathrm{h}$ & - & - & 162 & - & 139 & - & 202 & - & 324 \\
\hline FT (carbon) & $\mathrm{tCO}_{2} / \mathrm{h}$ & - & - & - & - & - & 107 & 107 & 107 & 107 \\
\hline Avoided & $\mathrm{tCO}_{2}$-eq/h & - & 127 & 283 & 87 & 225 & 122 & 319 & 311 & 627 \\
\hline
\end{tabular}


Table B5 (continued)

\begin{tabular}{|c|c|c|c|c|c|c|c|c|c|c|}
\hline & \multirow[t]{2}{*}{ Unit } & \multirow[t]{2}{*}{ REF } & \multicolumn{2}{|c|}{ BIG-CHP } & \multicolumn{2}{|c|}{ BIG- $\mathrm{H}_{2}$} & \multicolumn{2}{|c|}{ BIG-FT } & \multicolumn{2}{|c|}{ BIG-combi } \\
\hline & & & Vent & CCS & Vent & CCS & Vent & CCS & Vent & CCS \\
\hline CAPEX & $\mathrm{M} €$ & - & 266 & 328 & 264 & 268 & 571 & 582 & 765 & 783 \\
\hline OPEX $^{\mathrm{i}}$ & $\mathrm{M} € / \mathrm{y}$ & - & 16 & 19 & 16 & 16 & 34 & 34 & 45 & 46 \\
\hline
\end{tabular}

a Natural gas used in the base case for the production of steam, electricity and hydrogen.

b The capacity factors of the CHP units (power/steam production) and SR ( $\mathrm{H}_{2}$ production) are $91 \%$ and $56 \%$, respectively. To meet the current power and steam

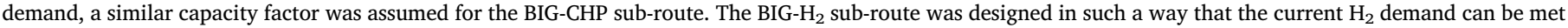
when operating the BIG train with a capacity factor of $91 \%(8000 \mathrm{~h} / \mathrm{y})$. For the BIG-FT sub-route, also a capacity factor of $91 \%$ was assumed.

c The model was set to replace $560 \mathrm{MW}$ of natural gas used as fuel for the in situ CHP units in sub-routes 1 (BIG-CHP) and 4 (BIG-combi). The CHP units were

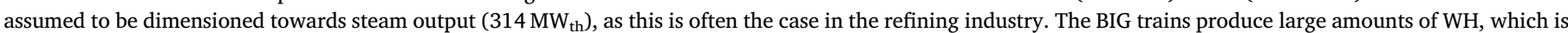

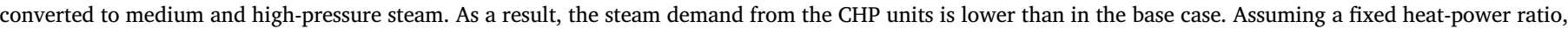

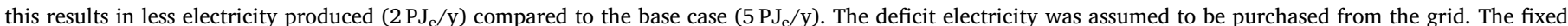
heat-power ratio was assumed, because of missing information on the CHP characteristics and steam quality.

$\mathrm{d}$ Excess heat in the gasification train is used for the production of excess steam.

e The fossil fuel replaced in the BIG-CHP and BIG- $\mathrm{H}_{2}$ sub-routes was considered to be natural gas. The small amount of refinery fuels entering these units in the

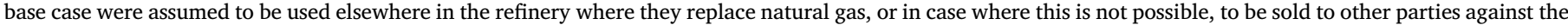

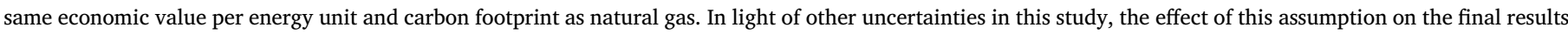
is expected to be minor.

${ }^{\mathrm{f}}$ In the BIG- $\mathrm{H}_{2}$ sub-route electricity is consumed for the production of hydrogen, which is purchased from the grid.

$g$ The in situ SR unit is assumed to operate at an efficiency of $75 \%$.

$\mathrm{h}$ The waste gases coming from the gasification process are combusted in a newly built steam turbine to produce electricity.

${ }^{i}$ Meerman et al. $[42,43]$ assumed the O\&M cost to be $4 \%$ of the total capital investment cost.

\section{B.4 Fast pyrolysis}

The second biomass route is the production and upgrading of pyrolysis oil from biomass as a means for generating infrastructure-ready renewable gasoline and diesel. At present, fast pyrolysis is the preferred process mode for the production of transport fuels as it exhibits high liquid yields [39]. Several advanced pyrolysis routes (e.g. catalytic pyrolysis) show promising economics, but are currently still at the R\&D or pilot stage [65]. A typical process for pyrolysis oil production comprises several steps [51]:

- Pre-treatment: drying and size reduction (pre-treatment) of lignocellulosic biomass.

- Fast pyrolysis: thermal decomposition of carbonaceous material in the absence of oxygen in a reactor to produce raw pyrolysis oil, which is a liquid rich in oxygenated hydrocarbons and pyrolytic lignin.

- Hydrotreating: upgrading of the raw, unstable pyrolysis oil to a conventional hydrocarbon fuel by deoxygenating the oxygenated hydrocarbons and pyrolytic lignin by means of pressurized hydrogen gas at moderate temperatures $\left(<400{ }^{\circ} \mathrm{C}\right)$ in a fixed bed reactor. The co-produced off-gas is sent to a PSA unit for recovery of hydrogen gas. The PSA tail gas is routed to the SR for hydrogen production and partly to the furnace that preheats the feed for the hydrotreater.

- Hydrocracking and product separation: the separation of stable pyrolysis oil into light and heavy fractions, the hydrocracking ( $\sim 425{ }^{\circ} \mathrm{C}$; 90 bar) of the heavy fractions into light fractions, and the separation of the light fractions into gasoline and diesel. The off-gas is sent to the SR.

Direct use of pyrolysis oil in existing hydrotreaters and hydrocrackers on the refinery site would require complete deoxygenation and a low acid number to prevent corrosion, assuming the existing processing units are not made of dedicated stainless steel. Furthermore, the integration of these flows in the refinery would require additional information on the spare capacity of the process units as well as on the core process streams to determine the effect on the other refinery flows. Therefore, the pyrolysis fuels were assumed to be produced in new processing units and in addition to the refinery product output mix, which was kept constant in this study. For the same reason, the required hydrogen was assumed to be produced in a new SR. An economic lifetime of 20 years was assumed. Although the fast pyrolysis process is already commercial, the upgrading step to transport fuels requires further development. Hence, we assume this technology to become available in the medium term. Fast pyrolysis and upgrading to transport fuels have been investigated in numerous studies, e.g. [13,66]. The techno-economic input data in the referenced studies varies considerably and is based on several assumptions regarding fuel yield, fuel energy content and process conditions. A PNNL study [44], which presents recent, detailed and publicly available data coming from several US research institutes, was used for the analysis. Similar to the BIG-FT sub-route, the size of the pyrolysis train was limited to $1000 \mathrm{MW}_{\mathrm{HHV}}$ feed input, which allows for a fair comparison of both options.

\section{References}

[1] European Commission. 2050 low-carbon economy 2018. < https://ec.europa.eu/ clima/policies/strategies/2050_en > [accessed April 3, 2018].

[2] IEA. Energy technology perspectives 2017. Paris (France): International Energy Agency; 2017.

[3] Rodrigues da Silva R, Mathias FR de C, Bajay SV. Potential energy efficiency improvements for the Brazilian iron and steel industry: fuel and electricity conservation supply curves for integrated steel mills. Energy 2018;153:816-24. https://doi.org/10.1016/j.energy.2018.04.055.

[4] Yáñez E, Ramírez A, Uribe A, Castillo E, Faaij A. Unravelling the potential of energy efficiency in the Colombian oil industry. J Clean Prod 2018;176:604-28. https://doi.org/10.1016/j.jclepro.2017.12.085.
[5] Saygin D, Wetzels W, Worrell E, Patel M. Linking historic developments and future scenarios of industrial energy use in the Netherlands between 1993 and 2040. Energy Efficiency 2012;6(2013):341-68. https://doi.org/10.1007/s12053-0129172-8.

[6] Fleiter T, Fehrenbach D, Worrell E, Eichhammer W. Energy efficiency in the German pulp and paper industry - a model-based assessment of saving potentials. Energy 2012;40:84-99. https://doi.org/10.1016/j.energy.2012.02.025.

[7] Saygin D, Gielen DJ, Draeck M, Worrell E, Patel MK. Assessment of the technical and economic potentials of biomass use for the production of steam, chemicals and polymers. Renew Sustain Energy Rev 2014;40:1153-67. https://doi.org/10.1016/ j.rser.2014.07.114.

[8] Kuramochi T, Ramírez A, Turkenburg W, Faaij A. Comparative assessment of $\mathrm{CO}_{2}$ capture technologies for carbon-intensive industrial processes. Prog Energy Combust Sci 2012;38:87-112. https://doi.org/10.1016/j.pecs.2011.05.001. 
[9] Leeson D, Mac Dowell N, Shah N, Petit C, Fennell PS. A Techno-economic analysis and systematic review of carbon capture and storage (CCS) applied to the iron and steel, cement, oil refining and pulp and paper industries, as well as other high purity sources. Int J Greenh Gas Control 2017;61:71-84. https://doi.org/10.1016/ j.ijggc.2017.03.020

[10] IEA. Renewable energy for industry. International Energy Agency, OECD 2017.

[11] IRENA. Renewable energy options for the industry sector: global and regional potential until 2030. Background to "Renewable Energy in Manufacturing" Technology Roadmap (IRENA, 2014a). Bonn (Germany); 2014.

[12] Fais B, Sabio N, Strachan N. The critical role of the industrial sector in reaching long-term emission reduction, energy efficiency and renewable targets. Appl Energy 2016;162:699-712. https://doi.org/10.1016/j.apenergy.2015.10.112.

[13] Boulamanti A, Moya JA. Energy efficiency and GHG emissions: prospective scenarios for the chemical and petrochemical industry. JRC Science for Policy Report (JRC105767/EUR 28471 EN). Luxembourg: Publications Office of the European Union; 2017.

[14] Johansson D, Rootzén J, Berntsson T, Johnsson F. Assessment of strategies for $\mathrm{CO}_{2}$ abatement in the European petroleum refining industry. Energy 2012;42:375-86. https://doi.org/10.1016/j.energy.2012.03.039.

[15] Fellaou S, Bounahmidi T. Evaluation of energy efficiency opportunities of a typical Moroccan cement plant: Part I. Energy analysis. Appl Therm Eng 2017;115:1161-72. https://doi.org/10.1016/j.applthermaleng.2017.01.010.

[16] IEA GHG. Understanding the cost of retrofitting $\mathrm{CO}_{2}$ capture in an integrated oil refinery - technical review 2017-TR8. Cheltenham (UK): International Energy Agency Greenhouse Gas R\&D Programme; 2017.

[17] Arellano-Garcia H, Ketabchi E, Ramirez Reina T. Comput Aided Chem Eng 2017;40:829-34. https://doi.org/10.1016/B978-0-444-63965-3.50140-9.

[18] Knoope MMJ, Meerman JC, Ramírez A, Faaij APC. Future technological and economic performance of IGCC and FT production facilities with and without $\mathrm{CO}_{2}$ capture: Combining component based learning curve and bottom-up analysis. Int $\mathrm{J}$ Greenh Gas Control 2013;16:287-310. https://doi.org/10.1016/j.ijggc.2013.01. 002

[19] Bühler F, Guminski A, Gruber A, Van Nguyen T, von Roon S, Elmegaard B. Evaluation of energy saving potentials, costs and uncertainties in the chemical industry in Germany. Appl Energy 2018;228:2037-49.

[20] Tesema G, Worrell E. Energy efficiency improvement potentials for the cement industry in Ethiopia. Enertgy 2015;93:2041-52. https://doi.org/10.1016/j. energy.2015.10.057.

[21] Andersson E, Karlsson M, Thollander P, Paramonova S. Energy end-use and efficiency potentials among Swedish industrial small and medium-sized enterprises a dataset analysis from the national energy audit program. Renew Sustain Energy Rev 2018;93:165-77. https://doi.org/10.1016/j.rser.2018.05.037.

[22] Kesicki F, Ekins P. Marginal abatement cost curves: a call for caution. Clim Policy 2012;12:219-36. https://doi.org/10.1080/14693062.2011.582347.

[23] OANDA. Currency converter; 2014. <http://www.oanda.com/ > .

[24] IHS CERA. Downstream Capital Costs Index (DCCI); 2014. < http://www ihsindexes.com $>$.

[25] Larson ED, Jin H, Celik FE. Gasification-based fuel and electricity production from biomass, without and with carbon capture and storage. New Jersey (United States): Princeton Environmental Institute, Princeton University; 2005.

[26] NEA. Monitoringsplan Shell Nederland raffinaderij BV. the Hague, (the Netherlands): Nederlandse Emissieautoriteit (Dutch Emission Authority); 2012.

[27] IEA. World energy outlook 2013. Paris (France): International Energy Agency; 2013.

[28] GEA. Global energy assessment toward a sustainable future. Laxenburg, (Austria): Cambridge University Press; 2012.

[29] CONCAWE. Oil refining in the EU in 2020, with perspectives to 2030. Report no. 1/13. Brussels (Belgium): Conservation of Clean Air and Water in Europe; 2013.

[30] Europia. European Petroleum Industry Association - Annual Report 2012. Brussels (Belgium): European Petroleum Industry Association; 2012.

[31] CONCAWE. Impact of product quality and demand evolution on EU refineries at the 2020 horizon - $\mathrm{CO}_{2}$ emissions trend and mitigation options. Report no. 8/08. Brussels (Belgium): Conservation of Clean Air and Water in Europe; 2008.

[32] IEA. World energy outlook 2017. Paris (France): International Energy Agency; 2017.

[33] Andersson V, P-åke Franck, Berntsson T. Temperature dependence of heat integration possibilities of an MEA scrubber plant at a refinery. Energy ProcediaKyoto (Japan) 2013;0:9

[34] Worrell E, Corsten M, Galitsky C. Energy efficiency improvement and cost saving opportunities for petroleum refineries - an ENERGY STAR guide for energy and plant managers. Utrecht (the Netherlands). 2015.

[35] Berghout N, van den Broek M, Faaij A. Techno-economic performance and challenges of applying $\mathrm{CO}_{2}$ capture in the industry: a case study of five industrial plants. Int J Greenh Gas Control 2013:17. https://doi.org/10.1016/j.ijggc.2013. 04.022 .

[36] Kvamsdal HM, Bolland O, Maurstad O, Jordal K. A qualitative comparison of gas turbine cycles with $\mathrm{CO}_{2}$ capture. A Qual. Comp. gas turbine cycles with $\mathrm{CO}_{2}$ capture. Proc. Proc. 8th Int. Conf. Greenh. Gas Control Technol., Trondheim (Norway). 2006.

[37] Meerman JC, Hamborg ES, van Keulen T, Ramírez A, Turkenburg WC, Faaij APC. Techno-economic assessment of $\mathrm{CO}_{2}$ capture at steam methane reforming facilities using commercially available technology. Int J Greenh Gas Control 2012;9:160-71. https://doi.org/10.1016/j.ijggc.2012.02.018.

[38] Berghout N, van den Broek M, Faaij A. Techno-economic performance and challenges of applying $\mathrm{CO}_{2}$ capture in the industry: a case study of five industrial plants. Int J Greenh Gas Control 2013;17:259-79. https://doi.org/10.1016/j.ijggc.
2013.04.022.

[39] Balat M, Balat M, Kirtay E, Balat $\mathrm{H}$. Main routes for the thermo-conversion of biomass into fuels and chemicals. Part 1: pyrolysis systems. Energy Convers Manage 2009;50:3147-57. https://doi.org/10.1016/j.enconman.2009.08.014.

[40] Faaij A. Modern biomass conversion technologies. Mitig Adapt Strateg Glob Chang 2006;11:335-67. https://doi.org/10.1007/s11027-005-9004-7.

[41] Tijmensen MJA, Faaij APC, Hamelinck CN, van Hardeveld MRM. Exploration of the possibilities for production of Fischer Tropsch liquids and power via biomass gasification. Biomass Bioenergy 2002;23:129-52. https://doi.org/10.1016/S09619534(02)00037-5.

[42] Meerman JC, Ramírez A, Turkenburg WC, Faaij APC. Performance of simulated flexible integrated gasification polygeneration facilities, Part B: economic evaluation. Renew Sustain Energy Rev 2012;16:6083-102. https://doi.org/10.1016/j. rser.2012.06.030.

[43] Meerman JC, Ramírez A, Turkenburg WC, Faaij APC. Performance of simulated flexible integrated gasification polygeneration facilities. Part A: a technical-energetic assessment. Renew Sustain Energy Rev 2011;15:2563-87. https://doi.org/ 10.1016/j.rser.2011.03.018.

[44] PNNL. Process Design and Economics for the Conversion of Lignocellulosic Biomass to Hydrocarbon Fuels - Fast Pyrolysis and Hydrotreating. Washington D.C. (USA): Pacific Northwest National Laboratory (PNNL), National Renewable Energy Laboratory (NREL), Idaho National Laboratory (INL); 2013.

[45] Berghout N, Kuramochi T, van den Broek M, Faaij A. Techno-economic performance and spatial footprint of infrastructure configurations for large scale $\mathrm{CO}_{2}$ capture in industrial zones. A case study for the Rotterdam Botlek area (part A). Int J Greenh Gas Control 2015;39:256-84. https://doi.org/10.1016/j.ijggc.2015.05. 019.

[46] Ecofys. Sectoral Emission Reduction Potentials and Economic Costs for Climate Change (SERPEC-CC) - Industry \& refineries sector. Utrecht (the Netherlands): Ecofys; 2009.

[47] Szklo a, Schaeffer R. Fuel specification, energy consumption and $\mathrm{CO}_{2}$ emission in oil refineries. Energy 2007;32:1075-92. https://doi.org/10.1016/j.energy.2006. 08.008 .

[48] Holmgren K, Sternhufvud C. $\mathrm{CO}_{2}$-emission reduction costs for petroleum refineries in Sweden. J Clean Prod 2008;16:385-94. https://doi.org/10.1016/j.jclepro.2006. 11.008.

[49] Bridgwater AV. Review of fast pyrolysis of biomass and product upgrading. Biomass Bioenergy 2012;38:68-94. https://doi.org/10.1016/j.biombioe.2011.01. 048 .

[50] Moret S, Codina Gironès V, Bierlaire M, Maréchal F. Characterization of input uncertainties in strategic energy planning models. Appl Energy 2017;202:597-617. https://doi.org/10.1016/j.apenergy.2017.05.106.

[51] PNNL. Production of gasoline and diesel from biomass via fast pyrolysis, hydrotreating and hydrocracking: a design case. Richland, Washington (US): Pacific Northwest National Laboratory; 2009.

[52] Johansson Daniella, Berntsson Thore, Franck P-Å. Integration of Fischer-Tropsch fuel production with a complex oil refinery. Int J Environ Sustain Dev 2014;13:50-73.

[53] Lindsay I, Lowe C, Reddy S, Bhakta M, Balkenende S. Designing a climate friendly hydrogen plant. GHGT-9. Energy Procedia 2009;1:4095-102. https://doi.org/10. 1016/j.egypro.2009.02.217.

[54] Damen K, Van Troost M, Faaij A, Turkenburg W. A comparison of electricity and hydrogen production systems with $\mathrm{CO}_{2}$ capture and storage. Part A: review and selection of promising conversion and capture technologies. Prog Energy Combust Sci 2006;32:215-46. https://doi.org/10.1016/j.pecs.2005.11.005.

[55] Golombok M, Beintema K. Study theorizes use of geothermal sources for energy in refineries. Oil Gas J 2008(6):106.

[56] IEA GHG.. Evaluation and analysis of water usage of power plants with $\mathrm{CO}_{2}$ capture. Report: 2010/05. Cheltenham (UK): International Energy Agency Greenhouse Gas R\&D Programme; 2010.

[57] EIA. Data series annual industrial natural gas prices in the United States. 2014.

[58] Rootzén J, Johnsson F. Exploring the limits for $\mathrm{CO}_{2}$ emission abatement in the EU power and industry sectors-awaiting a breakthrough. Energy Policy 2013;59:443-58. https://doi.org/10.1016/j.enpol.2013.03.057.

[59] European Commission. Refinery Capacities and Balances (EU27); 2009.

[60] IEA. Energy technology perspectives 2012 - pathways to a clean energy system executive summary. Paris (France): International Energy Agency; 2012.

[61] ZEP. The costs of $\mathrm{CO}_{2}$ transport - post-demonstration CCS in the EU. Brussels (Belgium): European Technology Platform for Zero Emission Fossil Fuel Power Plants; 2011.

[62] ZEP. The costs of $\mathrm{CO}_{2}$ storage - post-demonstration CCS in the EU. Brussels (Belgium): European Technology Platform for Zero Emission Fossil Fuel Power Plants; 2011.

[63] Berghout N, van den Broek M, Faaij A. Deployment of infrastructure configuration for large-scale $\mathrm{CO}_{2}$ capture in industrial zones a case study for the Rotterdam Botlek area (part B). Int J Greenh Gas Control 2017;60. https://doi.org/10.1016/j ijggc.2017.02.015.

[64] Balat M, Balat M, Kirtay E, Balat H. Main routes for the thermo-conversion of biomass into fuels and chemicals. Part 2: gasification systems. Energy Convers Manage 2009;50:3158-68. https://doi.org/10.1016/j.enconman.2009.08.013.

[65] NREL. The Feasibility of Producing and Using Biomass-Based Diesel and Jet Fuel in the United States. Golden, Colorado (USA): National Renewable Energy Laboratory (NREL); 2013.

[66] NREL. Techno-economic analysis of biomass fast pyrolysis to transportation fuels Golden, Colorado (USA): National Renewable Energy Laboratory (NREL); 2010.

[67] NEA. Milieujaarverslag 2012 Shell Nederland Raffinaderij BV. the Hague, (the 
Netherlands): Nederlandse Emissieautoriteit (Dutch Emission Authority); 2013.

[68] van Horssen A, Kuramochi T, Jozwicka M, Koornneef J, van Harmelen T, Ramírez Ramírez A. The impacts of $\mathrm{CO}_{2}$ capture technologies in power generation and industry on greenhouse gases emissions and air pollutants in the Netherlands. Utrecht (the Netherlands): TNO Built Environment and Geosciences; 2009.

[69] Rabou LPLM, Grift JM, Conradie RE, Fransen S. Microgasturbine voor laagcalorisch stookgas uit biomassa. ECN-E-06-026. Petten (the Netherlands): ECN, Energieonderzoek Centrum Nederland; 2006.

[70] Brouwer AS, van den Broek M, Zappa W, Turkenburg WC, Faaij A. Least-cost options for integrating intermittent renewables in low-carbon power systems. Appl Energy 2016;161:48-74. https://doi.org/10.1016/j.apenergy.2015.09.090.

[71] ConBio. Industrial Pellet prices in Euro slightly down according to Pix Pellet Nordic Index. January 21, 2014; 2014. < http://www.conbio.info/post/industrialpellet-prices-in-euro-slightly-down-according-to-pix-pellet-nordic-index/ >

[72] Agentschap NL. Protocol Monitoring Hernieuwbare Energie. Update 2010. Methodiek voor het berekenen en registeren van de bijdrage van hernieuwbare energiebronnen 2010; Buck; 2010.

[73] van den Broek M, Veenendaal P, Koutstaal P, Turkenburg W, Faaij A. Impact of international climate policies on $\mathrm{CO}_{2}$ capture and storage deployment: Illustrated in the Dutch energy system. Energy Policy 2011;39:2000-19. https://doi.org/10. 1016/j.enpol.2011.01.036.

[74] Batidzirai B, Van Der Hilst F, Meerman H, Junginger MH, Faaij APC. Optimization potential of biomass supply chains with torrefaction technology. Biofuels Bioprod Biorefining Soc Chem Ind 2013:5-7. https://doi.org/10.1002/bbb.1458.

[75] Batidzirai B, Junginger HM, Faaij APC. Current and future technical, economic and environmental feasibility of maize and wheat residues supply for biomass energy application: Illustrated for South Africa. Biomass Bioenergy 2016;92:106-29. https://doi.org/10.1016/j.biombioe.2016.06.010.

[76] Batidzirai B, Mignot APR, Schakel WB, Junginger HM, Faaij APC. Biomass torrefaction technology: techno-economic status and future prospects. Energy 2013;62:196-214. https://doi.org/10.1016/j.energy.2013.09.035.

[77] Ecoinvent. Ecoinvent database v2.2, SimaPro; 2010

[78] IEA GHG. $\mathrm{CO}_{2}$ abatement in oil refineries: fired heaters. Report: Ph3/31. Cheltenham (UK): International Energy Agency Greenhouse Gas R\&D Programme; 2000.

[79] Bolland O. Assessment of cogeneration systems performance. Compendium for the EEU-course "Fremtidsrettet energiplanleeging" (Planning of energy technologies for the future). Trondheim (Norway): Norwegian University of Science and Technology; 1993.

[80] Kuramochi T, Faaij A, Ramírez A, Turkenburg W. Prospects for cost-effective postcombustion $\mathrm{CO}_{2}$ capture from industrial CHPs. Int J Greenh Gas Control 2010;4:511-24.

[81] Meerman JC, Knoope MMJ, Ramírez A, Turkenburg WC, Faaij APC. Technical and economic prospects of coal- and biomass-fired integrated gasification facilities equipped with CCS over time. Int J Greenh Gas Control 2013;16:311-23. https:// doi.org/10.1016/j.ijggc.2013.01.051.

[82] Blok K. Introduction to energy analysis. Utrecht University, Utrecht (the Netherlands): Techne Press; 2007.

[83] Grahn M, Azar C, Lindgren K, Berndes G, Gielen D. Biomass for heat or as transportation fuel? A comparison between two model-based studies. Biomass Bioenergy 2007;31:747-58. https://doi.org/10.1016/j.biombioe.2007.05.001.

[84] DACE. DACE-Pricebooklet Aart Freriks 28th ed. Doetinchem (the Netherlands): Dutch Association of Cost Engineers (DACE); 2011.

[85] Bradley D, Hektor B, Wild M, Deutmeyer M, Schouwenberg P, Hess RR, et al. Long distance biomass supply chains. IEA bioenergy task 40: sustainable bioenergy trade. Paris (France): International Energy Agency; 2014.

[86] van Straelen J, Geuzebroek F, Goodchild N, Protopapas G, Mahony L. $\mathrm{CO}_{2}$ capture for refineries, a practical approach. Ninth Int Conf Greenh Gas Control Technol 2010;4:316-20. https://doi.org/10.1016/j.ijggc.2009.09.022.

[87] de Mello LF, Pimenta RDM, Moure GT, Pravia ORC, Gearhart L, Milios PB, et al. A technical and economical evaluation of $\mathrm{CO}_{2}$ capture from FCC units. Proc 9th int conf greenh gas control technol (GHGT-9), 16-20 Novemb 2008, Washington DC, USA, vol. 1. 2009. p. 117-24.

[88] NREL. Analyzing the Levelized Cost of Centralized and Distributed Hydrogen Production Using the H2A Production Model, Version 2. Technical Report NREL/ TP-560-46267. Golden, Colorado (USA): National Renewable Energy Laboratory; 2009.

[89] CESAR. D2.4.3 European Best Practice Guidelines for Assessment of CO2 Capture Technologies. CO2 Enhanced Separation and Recovery. vol. CESAR D2.4. European Commission DG Research; 2011.

[90] Feron PHM. Progress in post-combustion $\mathrm{CO}_{2}$ capture. European $\mathrm{CO}_{2}$ Capture and Storage Conference Towards Zero Emission Power Plants. 2005.

[91] Peeters ANM, Faaij APC, Turkenburg WC. Techno-economic analysis of natural gas combined cycles with post-combustion $\mathrm{CO}_{2}$ absorption, including a detailed evaluation of the development potential. Int J Greenh Gas Control 2007;1:396-417. https://doi.org/10.1016/S1750-5836(07)00068-0.

[92] Hurst P, Walker G. Post-combustion separation and capture baseline studies for the CCP industrial scenarios. Carbon dioxide capture storage deep geol. form. Amsterdam: Elsevier Science; 2005. p. 117-31 [chapter 6].

[93] IEA GHG. Oxy combustion processes for $\mathrm{CO}_{2}$ capture from power plant. Report: 2005/9. Cheltenham (UK): International Energy Agency Greenhouse Gas R\&D Programme; 2005.
[94] ZEP. The costs of $\mathrm{CO}_{2}$ capture, transport and storage. Brussels (Belgium): Postdemonstration CCS in the EU; 2011.

[95] Nienoord M. Personal communication. Data on regeneration energy of monoethanolamine (MEA) and ADIP-X, and CAPEX of ADIP-X capture system using process simulation software Aspen Plus ${ }^{\circledast} .2012$

[96] NETL. Cost and performance baseline for fossil energy plants volume 1: bituminous coal and natural gas to electricity. Revision 2. DOE/2010/1397. USA National Energy Technology Laboratory; 2010.

[97] Batidzirai B, Schotman GS, Van der MW, Spek, Junginger M, Faaij APC. Technoeconomic performance of sustainable international bio-SNG production and supply chains on short and longer term. 2018. https://doi.org/10.1002/bbb.1911.

[98] Worrell E. Personal communication with energy efficiency expert Prof. Dr. Ernst Worrell of the Copernicus Institute of Sustainable Development on 10-12-2013 2013.

[99] de Wit M, Junginger M, Lensink S, Londo M, Faaij A. Competition between biofuels: Modeling technological learning and cost reductions over time. Biomass Bioenergy 2010;34:203-17. https://doi.org/10.1016/j.biombioe.2009.07.012.

[100] Hoogwijk M, Faaij A, de Vries B, Turkenburg W. Exploration of regional and global cost-supply curves of biomass energy from short-rotation crops at abandoned cropland and rest land under four IPCC SRES land-use scenarios. Biomass Bioenergy 2009;33:26-43. https://doi.org/10.1016/j.biombioe.2008.04.005.

[101] Uslu A, Faaij APC, Bergman PCa. Pre-treatment technologies, and their effect on international bioenergy supply chain logistics. Techno-economic evaluation of torrefaction, fast pyrolysis and pelletisation. Energy 2008;33:1206-23. https:// doi.org/10.1016/j.energy.2008.03.007.

[102] Rao M, Rubin ES, Berkenpas MB. An integrated modeling framework for carbon management technologies. Technical documentation: amine-based $\mathrm{CO} 2$ capture and storage systems for fossil fuel power plant. Pittsburgh, PA (USA): Carnegie Mellon University; 2004.

[103] Yagi Y, Mimura T, IIjima M, Ishida K, Yoshiyama R, Kamijo T, et al. Improvements of carbon dioxide capture technology. Proc. 7th int. conf. greenh. gas control technol., Vancouver (Canada). 2004. p. 1139-45.

[104] Knoope MMJ, Guijt W, Ramírez A, Faaij APC. Improved cost models for optimizing $\mathrm{CO}_{2}$ pipeline configuration for point-to-point pipelines and simple networks. Int $\mathrm{J}$ Greenh Gas Control 2014;22:25-46. https://doi.org/10.1016/j.ijggc.2013.12.016.

[105] Kreutz T, Williams R, Consonni S, Chiesa P. Co-production of hydrogen, electricity and $\mathrm{CO}_{2}$ from coal with commercially ready technology. Part B: economic analysis. Int J Hydrogen Energy 2005;30:769-84. https://doi.org/10.1016/j ijhydene.2004.08.001.

[106] Sipöcz N, Tobiesen A, Assadi M. Integrated modelling and simulation of a 400 MW NGCC power plant with $\mathrm{CO}_{2}$ capture. 10th int conf greenh gas control technol. 2011. p. 1941-8.

[107] Kuramochi T, Ramírez A, Turkenburg W, Faaij A. Techno-economic prospects for $\mathrm{CO}_{2}$ capture from distributed energy systems. Renew Sustain Energy Rev 2013;19:328-47. https://doi.org/10.1016/j.rser.2012.10.051.

[108] Allam R, White V, Ivens N, Simmonds M. The oxyfuel baseline: revamping heaters and boilers to oxyfiring by cryogenic air separation and flue gas recycle [chapte 26]. Carbon dioxide capture storage deep geol. formAmsterdam (the Netherlands): Elsevier Science; 2005. p. 451-75.

[109] Allam R, White V, Stein V, McDonald C, Ivens N, Simmonds M. Revamping heaters and boilers to oxyfiring-producing oxygen by ITM technology [chapter 30]. Carbon dioxide capture storage deep geol. form.Amsterdam (the Netherlands): Elsevier Science; 2005. p. 513-35.

[110] IEA GHG. $\mathrm{CO}_{2}$ capture from medium scale combustion installations. Report: 2007/ 7. Cheltenham (UK): International Energy Agency Greenhouse Gas R\&D Programme; 2007.

[111] Zanganeh KE, Shafeen A, Thambimuthu K. A comparative study of refinery fuel gas oxy-fuel combustion options for $\mathrm{CO}_{2}$ capture using simulated process data. Int. Conf. Greenh. Gas Technol 2004:1-6.

[112] Spero C. Callide oxyfuel project - status \& development. First international oxyfuel combustion conference. 2008.

[113] IEA GHG. $\mathrm{CO}_{2}$ capture in the cement industry. Report: 2008/3. Cheltenham (UK): International Energy Agency Greenhouse Gas R\&D Programme; 2008.

[114] ZEP. The costs of $\mathrm{CO}_{2}$ capture - post-demonstration CCS in the EUEuropean Technology Platform for Zero Emission Fossil Fuel Power Plants. Brussels (Belgium): ZEP; 2011.

[115] $\mathrm{C}+\mathrm{B}$ advies en expertise. $\mathrm{CO}$ en $\mathrm{CO} 2$ in brandgassen ( $\mathrm{CO}$ and $\mathrm{CO} 2$ in fuel gases); 2014. <http://www.cplusb.nl/Nieuws/CObrandgas.html >

[116] Appl M. Ammonia, methanol, hydrogen, carbon monoxide. modern production technologies hydrogen. nitrogen. J World Nitrogen Methanol Ind 1997:101-15 [Unknown chapter 4].

[117] Kiewiet J. Personal communication with industrial gas separation expert Jacques Kiewiet of Air Products on 02-04-2012 2012.

[118] INL. Technical evaluation study: HTGR-integrated hydrogen production via steam methane reforming (SMR) economic analysis. Project No. 23843. Idaho Falls, Idaho (USA): Idaho National Laboratory; 2010.

[119] Rutkowski M. Current (2005) hydrogen from SMR natural gas with CO2 capture and sequestration 2005. < http://www.hydrogen.energy.gov/h2a_prod_studies. html>.

[120] Simbeck DR. Hydrogen costs with $\mathrm{CO}_{2}$ capture. Mountain View, California (USA): SFA Pacific, Inc., Technology \& Economic Consultants; 2005. 